\title{
Challenges at the Intersection
} of thiman and Natural Systems

\section{September 2005}

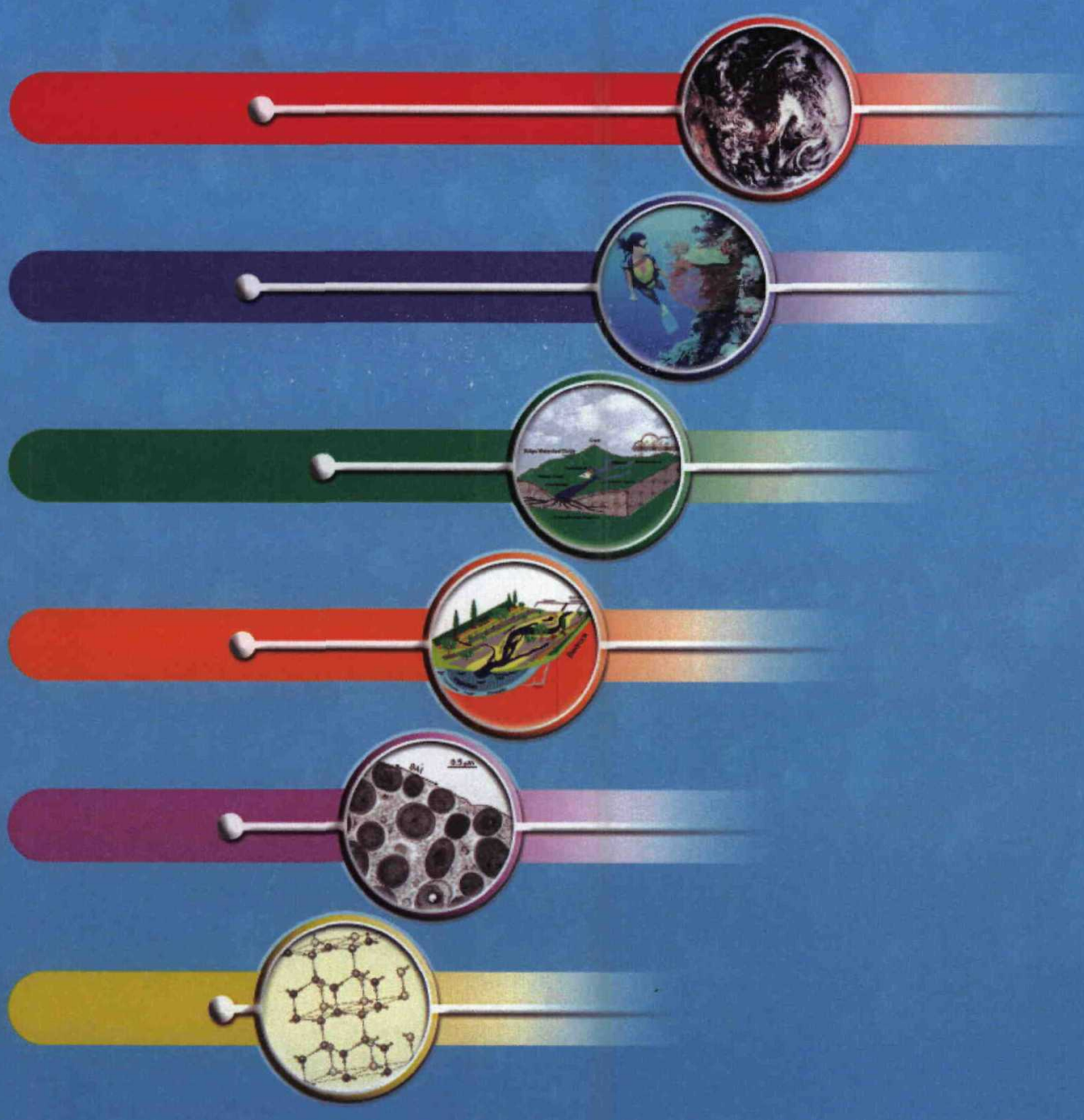

Report of the workshop held at Pacific Northwest National Laboratory September 15-16, 2004

Sponsored by the National Science Foundation and the

U,S. Department of Energy 


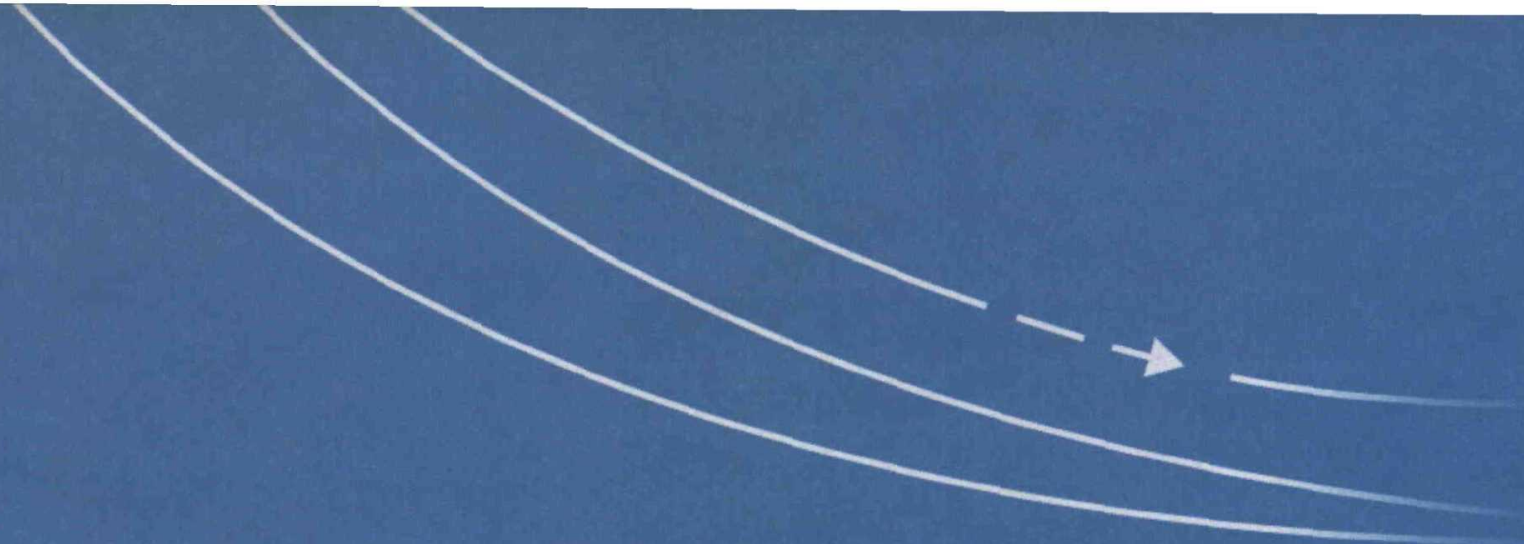

The workshop and preparation and publication of this report were sponsored by the National Science Foundation, under grant NSF OCE-0440816 to D. L. Skole, Michigan State University; and the U.S. Department of Energy's Office of Biological and Environmental Remediation, under Contract DE-AC05-76RL01830.

\section{DISCLAIMER}

This report was prepared as an account of work sponsored by an agency of the United States Government. Neither the United States Government nor any agency thereof, nor Battelle Memorial Institute, nor any of their employees, makes any warranty, express or implied, or assumes any legal liability or responsibility for the accuracy, completeness, or usefulness of any information, apparatus, product, or process disclosed, or represents that its use would not infringe privately owned rights. Reference herein to any specific commercial product, process, or service by trade name, trademark, manufacturer, or otherwise does not necessarily constitute or imply its endorsement, recommendaton, or favoring by the United States Government or any agency thereof, or Battelle Memorial Institute. The views and opinions of authors expressed herein do not necessarily state or reflect those ofthe United States Govermment or any agency thereof.

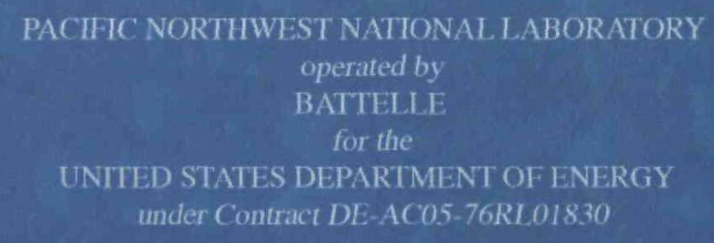

Printed in the United States of America

$$
\begin{aligned}
& \text { Available to DOE and DOE contractors from the } \\
& \text { Office of Scientific and Technical Information, } \\
& \text { P.O. Box 62, Oak Ridge, TN } 37831-0062 \text {; } \\
& \text { ph: (865) 576-8401 } \\
& \text { fax: (8650 576-5728 } \\
& \text { email: reports@adonis.osti.gov }
\end{aligned}
$$

Available to the public from the National Technical Information Service,

U.S. Department of Commerce, 5285 Port Royal Rd., Springfield, VA 22161

$$
\begin{aligned}
& \mathrm{ph}:(800) 553-6847 \\
& \text { fax: }(703) 605-6900
\end{aligned}
$$

email: orders@ntis.fedworld.gov

online ordering: http://www.ntis.gov/ordering.htm 


\section{DISCLAIMER}

This report was prepared as an account of work sponsored by an agency of the United States Government. Neither the United States Government nor any agency Thereof, nor any of their employees, makes any warranty, express or implied, or assumes any legal liability or responsibility for the accuracy, completeness, or usefulness of any information, apparatus, product, or process disclosed, or represents that its use would not infringe privately owned rights. Reference herein to any specific commercial product, process, or service by trade name, trademark, manufacturer, or otherwise does not necessarily constitute or imply its endorsement, recommendation, or favoring by the United States Government or any agency thereof. The views and opinions of authors expressed herein do not necessarily state or reflect those of the United States Government or any agency thereof. 


\section{DISCLAIMER}

Portions of this document may be illegible in electronic image products. Images are produced from the best available original document. 


\section{Water: Challenges at the Intersection of Human and Natural Systems}

Report of the workshop held at Pacific Northwest National Laboratory

September 15-16, 2004

Sponsored by the National Science Foundation, Michigan State University, and the U.S. Department of Energy

\section{Organizing Committee}

Jean H. Futrell, Pacific Northwest National Laboratory

Roy E. Gephart, Pacific Northwest National Laboratory

Ellen Kabat-Lensch, Eastern Iowa Community College District

Diane M. McKnight, University of Colorado

Ashanti Pyrtle, University of South Florida

Joshua P. Schimel, University of California Santa Barbara

Robyn L. Smyth, Knauss Marine Policy/NSF Fellow

David L. Skole, Michigan State University

John L. Wilson, New Mexico Institute of Mining and Technology

\section{Editors}

Robyn L. Smyth, National Science Foundation

Julie M. Gephart, Pacific Northwest National Laboratory 


\section{Foreword}

We are all aware of the importance of water to life on this planet. It is essential for all vital biological processes. As well, it is the medium or pathway for many serious pathogens and parasites that affect human health. It is the essential medium and molecule for most chemical reactions and processes.

It plays a vital role in climate, meteorology, and energy balance - from processes controlling latent heat flux to large-scale thermo-haline circulation in the oceans. From a geomorphological perspective, it plays an important role in shaping the landscape. And from a social science perspective, it is natural capital that greatly influences the formation of entire livelihood systems.

I am an interloper, because most of my work focuses on land science; but where I work in the Mekong system of Southeast Asia, you can see the profound influence of seasonal and inter-annual variations in the hydrologic cycle as it has shaped vast wet-rice farming systems. Multiple stressors from intensification of land use and climate events can have profound effects on whole social and food security systems that have evolved around water.

To see the broad influence of water, there may be no better case than that of the Balinese water temples. For centuries, farmers in the wet-rice terraces of Bali relied on priests of local water temples to coordinate irrigation among hundreds of farming communities. The Balinese agricultural tradition entailed complex religious, social, and technical processes that optimized water sharing on the Indonesian island, reduced pest infestations, and successfully yielded rice and other food crops.

We are all keenly aware of the politics and power brokering over water availability in places such as the lower Colorado or the Imperial Valley. And we can see the significance of the little notes appearing now in hotels everywhere, asking us to use our linens and towels more than once to conserve water. The availability of energy and freshwater will impact national growth and international politics, particularly among nations sharing common surface water and groundwater resources.

This workshop provided us with the chance to gather in the rain shadow of the High Cascades to consider some of the important questions and new research directions in water-related research-not from the perspective of any one of the aforementioned issues, or from the perspective of any one of our specialties or disciplines - but in the context of water as a complex environmental system. Complexity raises two questions:

1. Can human interventions in the water cycle set processes and trajectories in motion that we cannot readily see because they are masked by complexity and variation?

2. Can we begin to put all the pieces together in a way in which we can begin to forecast environmental changes related to water-and therefore intervene before irreparable environmental or social damage is done?

This workshop was an important community-based agenda-setting exercise. The NSF's new program on Environmental Research and Education has great potential to foster such interdisciplinary research. This workshop report will be looked at very carefully by the Advisory Committee for Environmental Research and Education (ACERE) as we attempt to articulate, advocate, and advise on new directions in research.

David L. Skole

Michigan State University

ACERE Chair 



\section{Organizing Committee Preface}

Many studies and workshops have addressed the critical importance of water quality and quantity to developing and sustaining human society. The committee responsible for organizing this workshop sought to focus attention on the complex coupling between human-engineered water systems and natural water phenomena. We brought together experts who focus on diverse aspects of human/natural water systems - ranging from hydrologic coupling to climate from the nanoscale to the watershed scale to the coastal ocean interface. With joint sponsorship from the U.S. Department of Energy (DOE) and the National Science Foundation (NSF), scientists and engineers from academic, federal, and national laboratories were brought together to share perspectives and broaden community understanding of ongoing fundamental and applied research on water as a complex environmental problem.

Energy production and use are intimately coupled to water; electrical power generation is second only to agriculture in water use, and together they account for ten times the water requirements for all other needs in the United States. Energy requirements for meeting society's needs for purified water and refined fuels are substantial and growing rapidly. Responding to environmental challenges requires increasingly sophisticated understanding of the coupling of waste streams and hazardous sites with subsurface and surface water flow. Changing industrial and energy production practices to minimize future environmental impact is a major scientific and societal challenge. Our planning for the workshop explicitly recognized the coupling between these mission needs for fundamental and applied science studies of water as a complex system at the intersection of human and natural systems.

We planned this workshop to provide a mix of opportunities for networking and discussion between people who seldom see each other at their own professional conferences. We selected keynote lecturers to give technical overviews of a broad range of topics and asked them to pinpoint the issues the Organizing Committee thought were important for discussion in the breakout groups. Participants were chosen to promote active and informed discussion of the relevant issues. Facilitators took notes and kept us somewhat on track. A successful workshop was the expected result, and this report is our product.

The venue for the workshop was the William R. Wiley Environmental Molecular Sciences Laboratory (EMSL) at the Pacific Northwest National Laboratory (PNNL) in Richland, Washington. The EMSL is a national scientific user facility funded by DOE's Office of Biological and Environmental Research. Nearly two thirds of its users are university students and faculty, many of who are funded by NSF grants. Workshop participants who toured EMSL became acquainted with its special facilities for work involving molecular-scale chemical and biological phenomena spanning the chemical, physical, and biological sciences, making it a highly appropriate facility in which to hold this workshop. Participants also toured the Hanford Reach National Monument where the last free-flowing stretch of the magnificent Columbia River flows across the Pacific Northwest. There, PNNL hydrologists and geologists described the unique ecology and hydrology of the arid Pacific Northwest and the unique natural and human-imposed challenges facing its future.

Jean Futrell

Pacific Northwest National Laboratory

Workshop Co-Chair and Organizing Committee Member 


\section{Executive Summary}

This workshop successfully established dialog between disciplinary scientists working at widely different scales of water as a complex environmental problem, ranging from molecular and biological phenomena at the nanoscale to regional precipitation where the influence of global climate change is clearly felt. Participants included scientists and program managers from diverse backgrounds who brought a correspondingly broad range of perspectives to this forum that highlighted overarching issues and themes. The workshop sought broad community input in developing ideas for interdisciplinary water science studies, identified critical gaps in water knowledge and research, and sought central themes that could shape research programs on water as a complex environmental system. A holistic approach was emphasized that addressed the multiple intersections between natural phenomena and human needs. Participants drew on their own experience as well as on a range of recent National Research Council and other community reports.

Three major scientific themes emerged:

- Coupling of cycles and process, with emphasis on the role of interfaces

- Coupling of human and natural systems across spatial and temporal scales

- Prediction in the face of uncertainty.

Coupling of cycles and process. The explicit coupling of hydrology, ecology, biology, chemistry, geology, and atmospheric science is needed to understand forcings and feedbacks among environmental processes and to predict system response to both land use/land cover changes and changing climate. The complex interactions of system functions and anthropogenic inputs (such as contaminant transport and compositional change) must be accounted for in testable ways. Because interfaces produce complex interactions and dynamics, and because phenomena at interfaces are poorly understood, resolving these processes using an appropriate mix of theory, modeling, and measurement is essential to improve our understanding of fluxes and cycling of water, chemicals, and sediments at larger scales.

Coupling of human and natural systems. Ubiquitous feedback between human and water-related natural systems has profoundly affected both ecosystems and the quantity and quality of water supplies. Research is needed that systematically addresses the multiple linkages between human and natural systems across scales and between processes. This is essential to tackling applied water quantity and quality problems and bringing scientific understanding to bear on water management.

Prediction in the face of uncertainty. The major challenge for prediction science is the development of transferable theories and models that integrate across broad scales in space and time the coupled processes linking human and natural systems. Scientifically focused acquisition of data from a combination of space- and ground-based observations that are then input into computationally efficient models will lead to new understanding of water as a complex system. Feedback of model predictions into the design of experiments and observation networks will lead to models for predicting outcomes of water resource management strategies. Model uncertainty should be explicitly recognized and quantified, then reduced through judicious coupling of increasingly advanced models with more advanced experimental observations.

Two overarching science needs were identified:

- Observation systems, sensors, and infrastructure

- Data management and synthesis. 
Observation systems, sensors, and infrastructure. There is an urgent need for development of realtime monitoring instruments, especially new sensor and sensor networking technologies, and for their integration into observation systems. Observing system designs should explicitly recognize and address the nonlinear coupling and intrinsic complexity of water-related environmental systems from molecular to continental scales. Especially needed are networked large-scale, long-term observatories of hydrologic systems in which human intervention is treated explicitly. Laboratory facilities for experimentation and observation at the smallest scales also are needed. New tools in these labs should include nondestructive microscopes and more sensitive molecular spectroscopes for hydrated environmental samples and spatially resolved and compound specific measurement and speciation techniques for the nanoscale and microscale. Genomic methods are needed for complex, poorly culturable microbial communities. Another major infrastructure limitation is in data handling and computational facilities. The necessary evolution of computer modeling will be fundamentally limited by the computational resources available to the community.

Data management and synthesis. Our capacity to address some of the complex, interdisciplinary research issues, including detection of environmental change, depends on the availability of high-quality data over a range of spatial and temporal scales. There is a need to integrate databases from disparate disciplines and establish open-access protocols and a mechanism for maintaining data over time. Coordination and implementation of metadata standards are essential. A possible approach is the creation of a public database where all researchers can deposit and retrieve environmental data that meet a predetermined standard of quality. Improved access to and coordination of such a database will enable new opportunities for interdisciplinary synthesis activities, integrated modeling, and theoretical developments.

Two barriers to progress were explicitly recognized:

- Education and institutional barriers

- Integration of science and policy.

Education and institutional barriers. Scientific solutions to water as a complex environmental problem demand an interdisciplinary approach; limited progress will be made with existing approaches that divide the problem into dozens of bins. Institutions, including professional societies, universities. and federal agencies, must play a larger role in bringing together the multiple disciplines enumerated in this document. No individual or small group of individuals has the expert knowledge to address the scope of problems that must be addressed for rapid progress to be achieved. Team science needs to be explicitly recognized and rewarded, and educational reform to encourage interdisciplinary research is needed.

Integration of science and policy. Science is done for the benefit of society. Water resource management is a special case in that water laws, governance structures, and agencies are constituted and focus on local or regional issues while water science has global dimensions. There is an obligation for the water science community to identify and articulate the technical issues that support policy decisions. Connecting scientific understanding to practitioners is needed to close gaps between "state of the art" and "state of the practice." New decision-making tools are needed that represent the complex coupling of natural and human systems and capture the risk of negative consequences, quantify this uncertainty, and discriminate between large and small problems. 


\section{Contents}

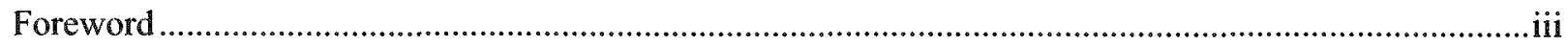

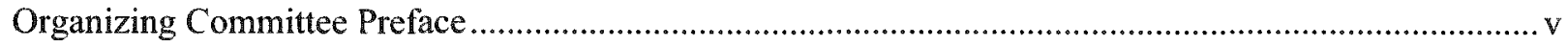

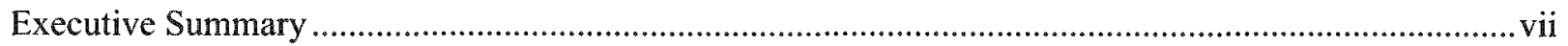

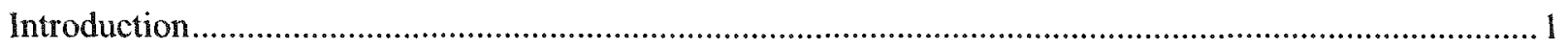

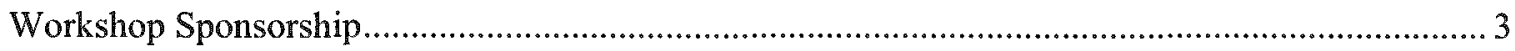

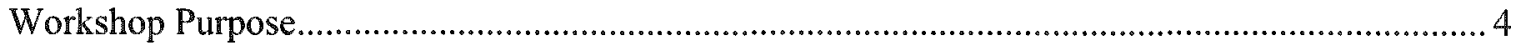

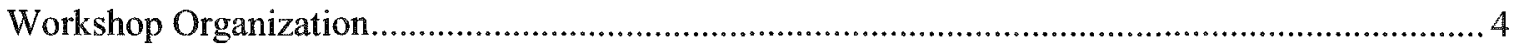

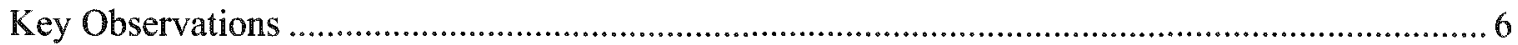

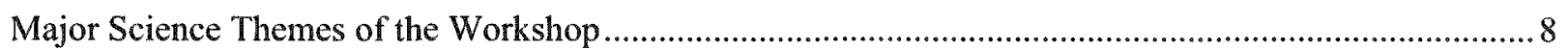

Theme 1: Coupling Cycles and Processes Across Disciplines ................................................... 8

Theme 2: Coupling Human and Natural Systems Across Spatial and Temporal Scales ............... 10

Theme 3: Improving Prediction Through Advancements in Theory and Observation ..................11

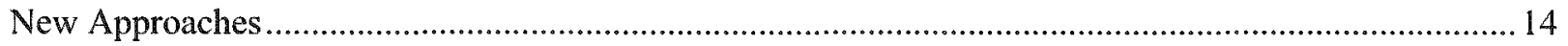

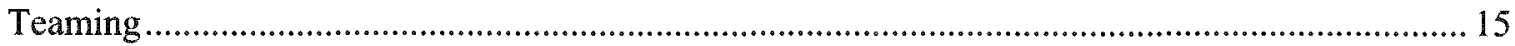

Observing Systems, Sensors, Data, and Infrastructure .................................................... 15

Overcoming Educational and Institutional Barriers ........................................................... 17

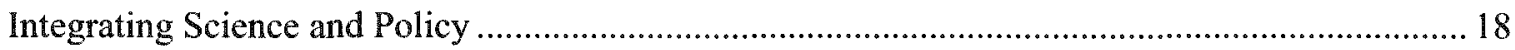

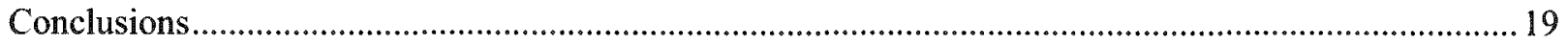

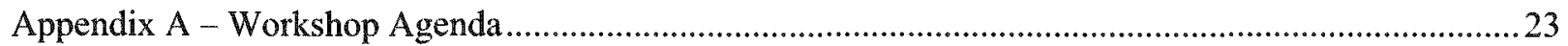

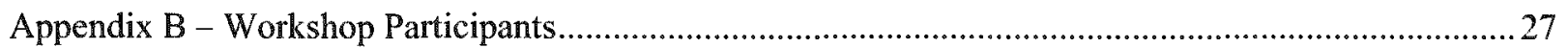

Appendix C - Summaries of Keynote Lectures............................................................................29

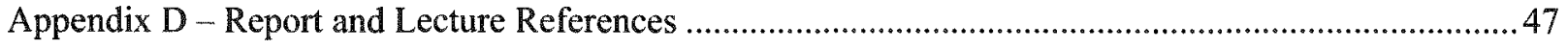




\section{Introduction}

Thoroughly conscious ignorance is the prelude to every real advance in science.

The labor of careful measurement has been rewarded by the discovery of new fields of research and by the development of new scientific ideas.

-James Clerk Maxwell

There is growing recognition about the critical role water plays in sustaining people and society (e.g., Vandas et al. 2002, WWAP 2003, NRC 2001 and 2004, NCSE 2004). Civilizations throughout time have applied their knowledge and technology to secure water for safe consumption and waste disposal and to reduce vulnerability to flooding and other extreme events. These are fundamental human pursuits that continue to challenge human societies today. The dominant approach in the last century was the construction of dams, pipelines, treatment plants, and other forms of infrastructure (Gleick 2003). Despite these massive investments, providing water of adequate quality and quantity to the world's population remains an immense and growing challenge.

Freshwater is increasingly scarce in large population centers and will place limits on development and security in many areas of the world (Figure 1). In other places, there are equally pressing societal problems resulting from flooding and an overabundance of water, most recently and notably in the Gulf Coast region of the United States (Figure 2). Meanwhile, aquatic systems are ubiquitously impacted by contamination, and declines from desiccation

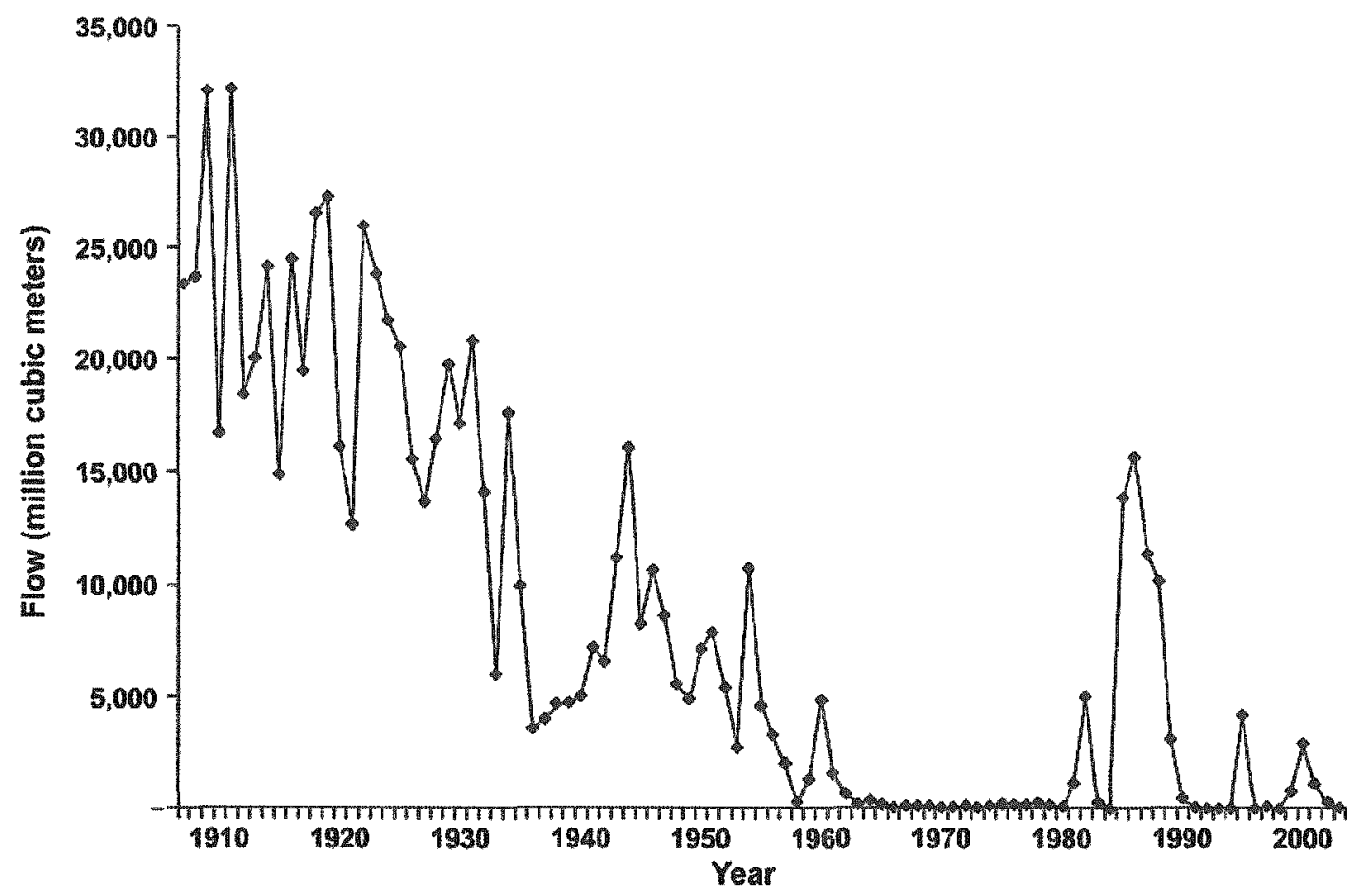

Figure 1. As shown, flows reaching the Colorado River delta have dropped to near zero in most years (Excerpted with permission from Gleick, PH. 2003. "Global freshwater resources: soft-path solutions for the 21 st century." Science 302:1524, Copyright 2003 AAAS). 


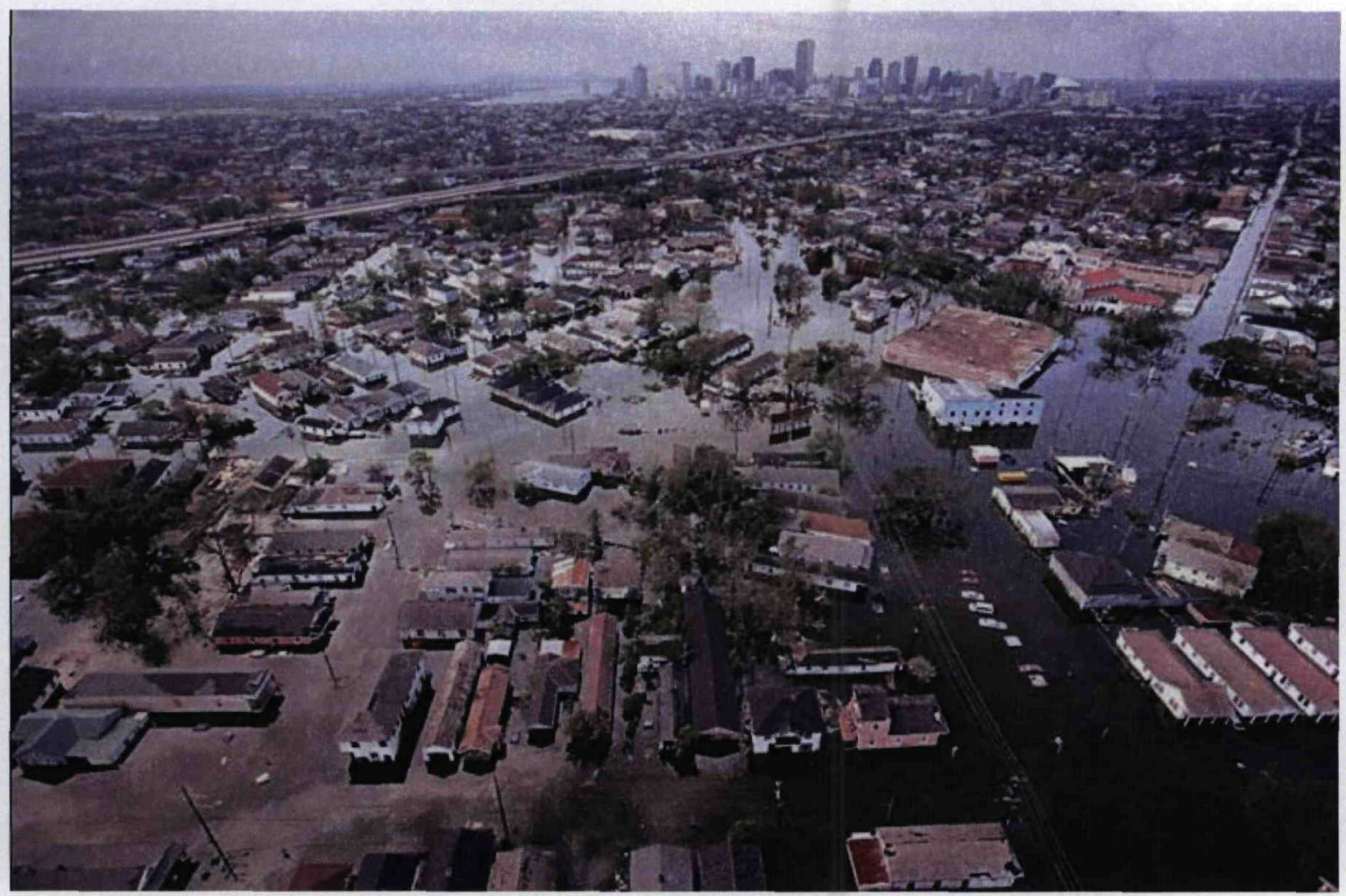

Vincent Laforet/Sipa Press

Figure 2. The tragedy of Hurricane Katrina's encounter with New Orleans illustrates the worst possible scenario of too much water in too short a time. Loss of wetlands and coastal subsidence from oil drilling aggravated the effect of storm surge that ruptured levees and flooded the city.

are striking (e.g., Lake Chad, Colorado River, Aral Sea). In the United States, projected growth in demand for clean, inexpensive, and sustainable energy is inextricably linked to that for clean, abundant, and inexpensive water (Figure 3). The high economic, environmental, and social costs of large infrastructure are increasingly acknowledged, and construction is on the decline (Gleick 2003). The regulation of water with the existing physical infrastructure will continue to be challenging, especially under the dynamic changes in the hydrologic cycle that may result from the accumulation of greenhouse gases in the atmosphere.

While there have been significant advances over the years in understanding the basic framework and dynamics of aquatic systems, we face an urgency to move research beyond singular terrestrial, atmospheric, surface, and subsurface disciplines into broader interdisciplinary approaches that link research investments with advancements in technology and our grasp of short- to long-term social needs.

We face an urgency to move research beyond singular terrestrial, atmospheric, surface, and subsurface disciplines into broader interdisciplinary approaches that link research investments with advancements in technology and social needs.

New concepts and innovative approaches are needed to improve our understanding of the underlying biological, physical, and chemical processes that govern the quantity, quality, and accessibility of freshwater in natural and humandominated ecosystems on local to global scales. 


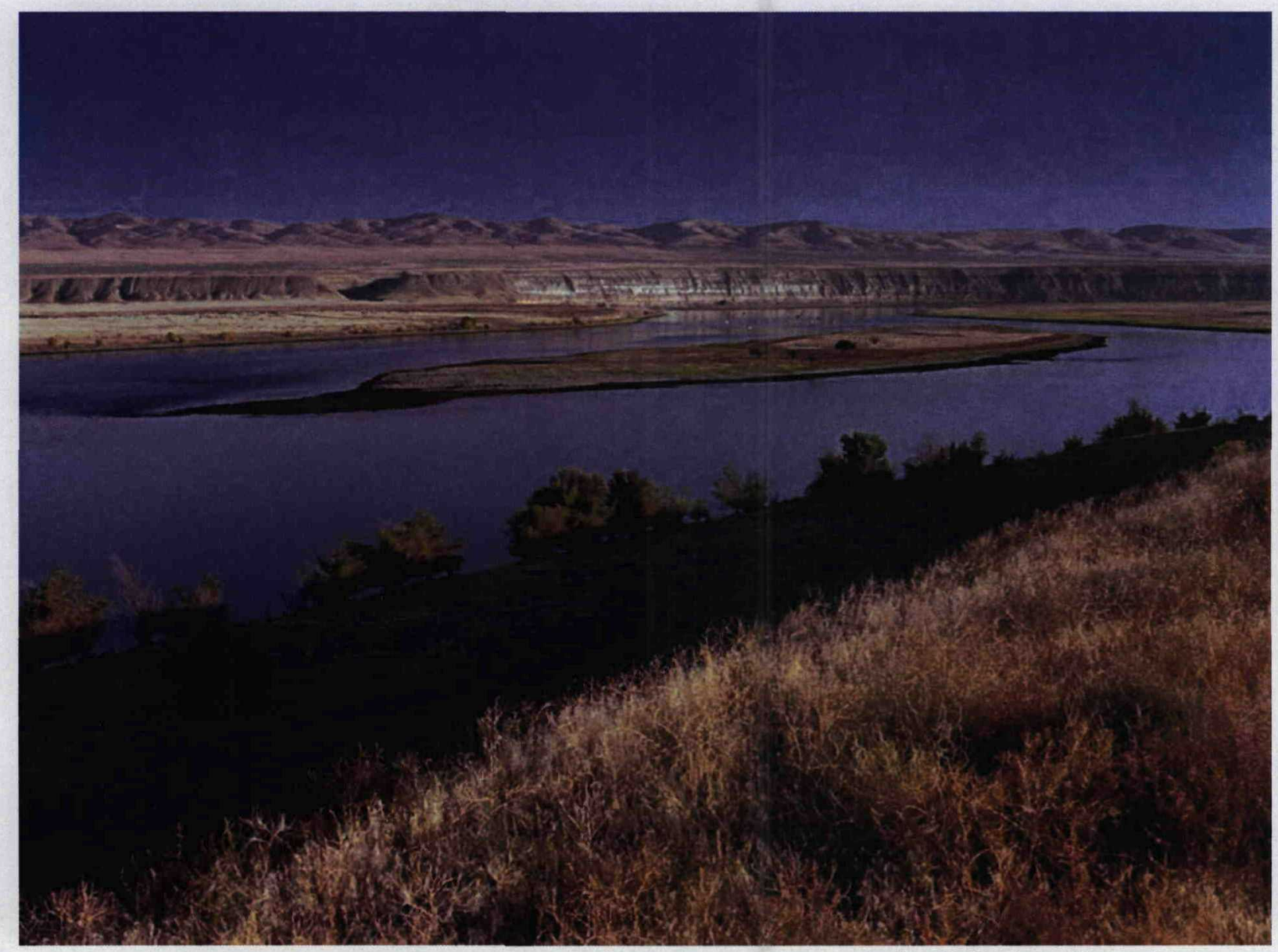

Pacific Northwest National Laboratory

Figure 3. The Columbia River is typical of major river systems in the arid West that are heavily managed for recreation, water supply, power generation, irrigation, fish, and wildlife ecology by an extensive series of dams. The Hanford Reach, on which Richland and PNNL are situated, is the only free-flowing stretch of the Columbia River.

To increase our ability to maintain viable supplies of freshwater, we need both basic research and an improved understanding of the politics of water including economics, law, and policy making under conditions of scientific and social uncertainty. To explore these complex issues and discuss interdisciplinary research needs, the National Science Foundation (NSF) and the U.S. Department of Energy (DOE) co-sponsored a workshop entitled "Water: Challenges at the Intersection of Human and Natural Systems" held at Pacific Northwest National Laboratory (PNNL) in Richland, Washington,

September 15-16, 2004.

\section{Workshop Sponsorship}

Water is the purview of at least 14 federal agencies. It is inherently multidisciplinary and calls for collaboration among institutions and among investigators. The integration of theory, modeling, experimentation, and observations across scales of time and space and the coupling of ecological, physical, and human systems are challenges of a magnitude not previously addressed in environmental science. This work is vitally important to society and is global in scope. Collectively, these factors argue for a paradigm shift in research and education of both scientists and the public. 
The integration of theory, modeling, experimentation, and observations across scales of time and space and the coupling of ecological, physical, and human systems are challenges of a magnitude not previously addressed in environmental science.
By jointly sponsoring this workshop, the NSF's Biocomplexity in the Environment Priority Area and DOE's Office of Biological and Environmental Research demonstrate their common interests in water research as a lead example of a complex environmental problem. The NSF has the central role in fundamental science research and in education of the next generation of science leaders. DOE has major responsibilities and capabilities for research and development in water, energy, and environmental sciences - all of which are closely coupled. In addition, DOE faces the cleanup of many complex hazardous chemical and radioactive waste sites across the United States resulting from facilities once used for the production of nuclear materials. Both agencies have distinctive means to tackle big problems that challenge our best scientific minds and relate to key societal concerns. Approaches of the two agencies are distinctly different, but they share the common goal of science serving society.

\section{Workshop Purpose}

This workshop was held to seek broad community input in developing ideas and identifying critical gaps in knowledge and research and central themes that could shape future research programs addressing water in the context of complex environmental systems (see workshop agenda in Appendix A).

Nearly 60 university and federal agency scientists and engineers involved in a range of water-related disciplines participated in the workshop (Appendix B). Traditionally, many water resource issues have been addressed from the perspective of distinct research communities or disciplinary interests. This workshop took a more holistic approach that emphasized the intersections between natural phenomena and human needs.

The workshop findings will be submitted to the Environmental Science Research Division of DOE's Office of Biological and Environmental Research and to the NSF Advisory Committee for Environmental Research and Education (ACERE). Our report to the ACERE will inform the committee as it formulates advice to NSF on how to advance the research, education. and infrastructure vision described in their January 2003 report Complex Environmental Systems - Synthesis for Earth, Life, and Socien, in the 2lst Century, and its March 2005 update Complex Environmental Systems - Pathways to the Future (http://www.nsf.gov/geo/ere/ereweb/ acere synthesis rpt.cfm).

\section{Workshop Organization}

The workshop was centered on six keynote lectures (summarized in Appendix C) that set the stage for two groups of breakout sessions. The lectures and the first group of breakout sessions focused on water at discrete spatial scales, namely the nano to microscale, river reach scale, watershed scale, the land-ocean interface, and the regional to global scale (Figure 4). The second set of breakout sessions emphasized integration across the scales discussed in the previous groups as well as water in the context of coupled human natural systems, breaking disciplinary barriers to interdisciplinary research and education, and providing science to benefit society.

In these sessions, participants were asked to capture important and timely science questions and identify other catalytic research opportunities. The ultimate goal is to describe the kinds of research essential to create a predictive understanding of water as a complex system that can provide guidance to policy makers. We 


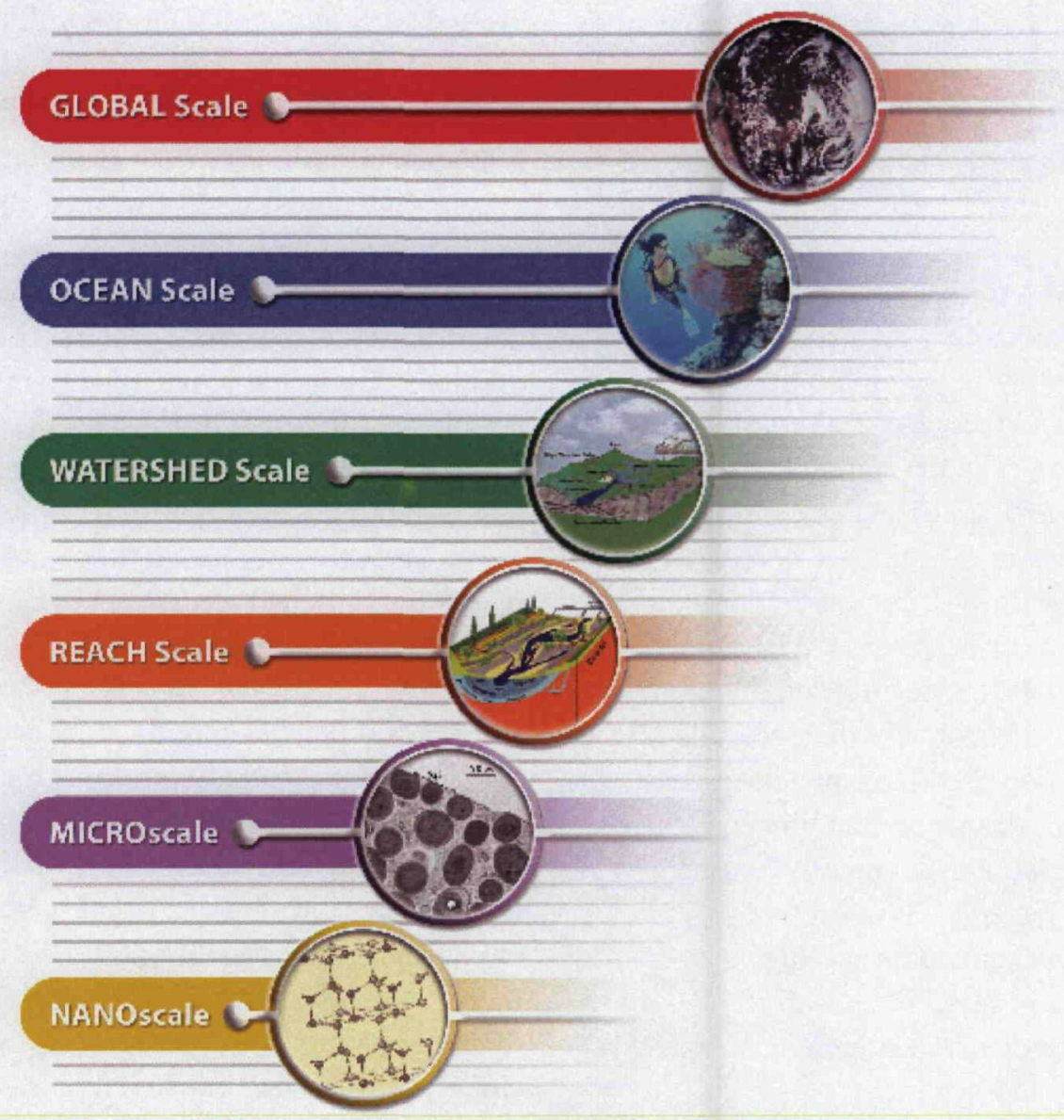

Figure 4. Water from the nanoscale to global scale.

have summarized those descriptions here; future workshops on topics suggested by our group will provide focus and definition to research programs with a 5 - to 10 -year time horizon.

The workshop was also organized to identify gaps across scales. Consequently, the scientific challenge of scaling, which is not unique to water, was discussed throughout the meeting and is pervasive in this report. Water is a complex environmental problem at every scale, beginning at the molecular scale and stretching to the global scale. The time dimension is a critical scaling issue that complements and challenges spatial scaling. Coupling of chemical and biological reactions with transport processes challenges our largest computers and most complex codes, and extending this information to the next larger scales in time and space requires new, integrated theoretical approaches. Research at all scales of inquiry and research that provides links systematically between scales are required to elucidate the complexities of the human-altered water cycle.

The challenge of scale is not simply one of extrapolation - taking measurements at one scale and multiplying them out to larger areasor interpolation-zooming in from a larger perspective to focus on a single spot. It involves transitions in the nature of the controlling drivers and processes and bridging the different approaches for measurement, experimentation, and modeling traditionally used by researchers from different disciplines. 
Research at all scales of inquiry and research that provides links systematically between scales are required to elucidate the complexities of the human-altered water cycle.

Another concept that permeated the meeting was that of interfaces. Interfaces, such as the boundary between sediment pore water and the overlying stream water and the terrestrial-coastal ocean margin, tend to produce complex interactions and dynamics that are poorly understood at all scales. Interfaces are the region where the most dramatic interactions occur, particularly at the nanoscale, where surface areas are large, self-assembly of organisms occurs, and biology mediates physical and chemical processes. To build a quantitative and predictive understanding of coupled hydrologic transport and biogeochemical processes, we must explicitly consider interfaces between systems with different hydrologic or biogeochemical properties. Resolving processes in these areas is difficult but necessary to improve understanding of water and constituent flux and cycling.

\section{Key Observations}

From the six lectures and meeting discussion came three key observations regarding the water issues addressed in the workshop.

\section{There is complexity at all scales in} hydrology. Holistic, system-level understanding depends upon our ability to integrate information methodically across scales in time and space. The special properties of water as the universal solvent define complexity at the molecular scale, and the dependence of the closely coupled interplay of biological and chemical processes on water concentration defines complexity at the nanoscale.

Moving to reaction and transport at the level of microns to meters fundamentally changes how environmental processes are described and studied. The interplay of surface and groundwater and modifications of these processes by human activities add additional dimensions of complexity. The investigation of fundamental processes such as precipitation, evaporation, and transpiration is distinct at the scale of landscapes, catchments, and riverbeds. This adds levels of complexity because scale determines the approaches for describing the problem. Each spatial unit also has its characteristically important time scales that collectively vary from picoseconds to centuries. Establishing the important scientific questions across such complexities in time and space is one of the principal challenges of this vast field

\section{Systematic approaches for cross-scale} integration are needed. Scaling up from the smallest scales (nano to micro) is in some sense the most straightforward in that the physical and chemical principles are well established, and laboratory measurements to calibrate and test models are most tractable. However, extending these concepts to understand, for example, temporal patterns of export of dissolved organic carbon from a small catchment, is very difficult. And the difficulties persist up and down the scale hierarchy. Clearly, substantial gains in scientific understanding of complex environmental systems call for a focused research program that explicitly confronts these difficult scaling problems.

An alternative approach, suggested by keynote speaker John Melack, is to ask questions and formulate hypotheses at the global scale. From this larger perspective, important processes and dynamics at smaller scales can be identified, examined, and scaled into understanding of phenomena occurring at larger scales. More specifically, we are challenged to learn how conservation laws will scale and how and when to parameterize smaller-scale details into largerscale models. Achieving this requires more interaction among scientists working at different scales, and progress toward hierarchical data and experimental design. In a broader sense, there is 
a need to develop theoretical approaches to scaling in complex systems that take into account specifically the coupling across boundaries and feedback inherent in nonlinear systems.

Another approach, introduced by keynote speaker Clifford Dahm and discussed later in more detail, is to use the river reach as the organizing unit to conceptualize, simulate, and study the complexity of water and its multifold couplings with natural and human systems. The time dependence and feedback among the coupled elements of the river reach must be considered, of course, and the intent of conceptualizing the problem in this way is to make it predictively useful. The importance of modeling and measurement, guided by integrating hypotheses, is the essence of this approach. Advances in all these areas, particularly in coupling strategically defined measurements with increasingly sophisticated predictive models, is our best hope for rapid progress.

\section{Reductionist science limits us to ${ }^{66} \mathrm{Just}$ So}

Stories." With traditional approaches practiced in the $20^{\text {th }}$ Century, we are limited in our ability to transfer knowledge from one system to another. As keynote speaker George Hornberger suggested in his talk, reports of work on catchment hydrology tend to resemble Rudyard Kipling's Just So Stories ("How the Leopard Got Its Spots," "How the Rhinoceros Got Its Skin," "The Elephant's (hild")-_that is, reductionist science that rigorously defines sources and sinks and is applied to pristine environments leads to theories and descriptions that apply to that site and to litile else.

Making the kind of progress that we must make in this century calls for a much more comprehensive systems approach. Although no prescriptive recommendations on how this might be accomplished were offered, it is clear that teams of researchers from diverse disciplines have to be engaged to meet this challenge. Development of appropriate strategies for gathering and assimilating appropriate data over time and free exchange of curated data among researchers worldwide are important elements of a comprehensive approach. Engagement of social scientists, planners, and educators at all levels as well as appropriate domain specialists is very important for understanding, communicating, and mitigating adverse human impact on water availability and quality.

We have greatly expanded our database for water and for environmental science in general over the past several decades. We are at the threshold of a virtual explosion of data acquisition in the next decade-from microscale sensor arrays to space-based remote sensing. A major challenge for this decade and for the future is the curation, synthesis, and dissemination of this information to researchers and to assist the development of advanced computational tools for converting data to information and information to graphical display.

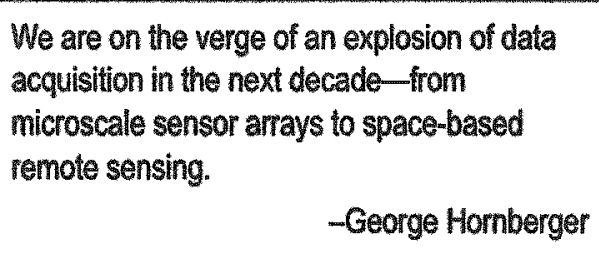

The connection between advanced observational networks and data libraries and human intelligence has to be graphical and interactive on a scale never before achieved. This coupling of information to human intellect can lead to the development of theoretical frameworks for analyzing, interpreting, and synthesizing these data into predictive models for water management. In the absence of a carefully architected systems approach linked to an environmental cyberinfrastructure base, we run the risk of devaluing the work by creating more "just so" stories. 


\section{Major Science Themes of the Workshop}

The challenge of providing adequate water quantity and quality for human use while maintaining the integrity of aquatic ecosystems cannot be met without advances in science and engineering. While these issues have been examined from disciplinary perspectives (e.g., geosciences: Vandas et al. 2002; chemical sciences: Norling et al. 2004), the objective of this workshop was specifically to identify interdisciplinary gaps that, if filled, will help policy and decision makers meet current and future water needs sooner versus later.

The challenge of providing adequate water quantity and quality for human use while maintaining the integrity of aquatic ecosystems cannot be met without advances in science and engineering.

To address these gaps, three science themes were emphasized throughout the workshop. Under the first theme, we discuss the needed advances in process-based understanding of the coupling of water and elemental cycles. Research encompassed by this theme will form a scientific and engineering foundation for providing sufficient water of sufficient quality to sustain human populations and the natural ecosystems upon which they depend. In the second theme, we examine the need to integrate the study of water systems and human systems. Water is a critical resource for humans, and the impacts of human activities on water resources are complex and only partially quantified. The third theme focuses on advancing predictive capabilities and systematically addressing uncertainty to provide highquality decision support.

\section{Theme 1: Coupling Cycles and Processes Across Disciplines}

Much research has been done to develop our understanding of the cycling of water, carbon, nitrogen, and other bioactive elements at global and regional scales. The challenge now lies in integrating and coupling these cycles in a quantitative and predictive manner and using this information to support sound policy and management decisions. To achieve this integration, research on the fundamental feedback and coupling between biogeochemical rates and processes with hydrologic processes is needed. The coupling of water movement and biogeochemical processes is relevant at scales ranging from the nanoscale - at which a molecule transitions from the solute phase to the solid phase by assimilation, sorption, or precipitation - to the macroscales of river channels and the global water cycle. Over this range of scales the fundamental scientific question may be posed as follows: How do fluid transport processes such as diffusion, turbulence, and flux influence and regulate biogeochemical cycling?

Because of important advances in instrumentation, modeling of fluid behavior, and microbial ecology, significant scientific opportunities now exist in coupling chemical-biological-hydrologic phenomena at the nano to microscale. Microbial communities mediate many processes and reactions that transform bioactive elements. Understanding the dynamic nature of the processes and reactions they mediate requires greatly improved characterization of the chemistry, biology, and physiology of aquatic microbial communities and their microenvironments. 
Water plays a key role in many of these processes and reactions by establishing the environmental condition through, for example, hydrologic influx containing missing reactants or anaerobic periods resulting from wetting and drying cycles. These microscale chemical and biological transformations of nutrients and pollutants are key to understanding element cycles and determining the overall water quality at larger scales.

Extending our understanding of processes and coupling in the microbial community across scales is key to resolving water-quality dynamics and improving understanding and coupling of elemental cycles at the global scale. We also need to scale down from the regional scale to understand how anthropogenic pressures and natural characteristics such as precipitation patterns and geologic setting trigger these microscale reactions and transformations. Understanding this cross-scale feedback will require innovative approaches that include coupling laboratory, field, and modeling studies.

Interfaces tend to have steep chemical gradients and may result in "hot spots" of biogeochemical reactivity (McClain et al. 2003). The vadose zone is a specific interfacial environmental system where unsaturated water conditions promote complex, highly nonlinear coupling of processes.

Another important example of an interface is the hyporheic zone, the zone adjacent to and underneath a stream or river where water in surface drainage systems and shallow groundwater mix with sediment surfaces and associated biofilms (Figure 5). Studies have shown that reactions occurring in the hyporheic zone can control the concentrations of both nutrients and contaminants in surface water.

At a regional to global scale, the near-shore coastal ocean is another poorly understood interface (Figure 6). Because of complex

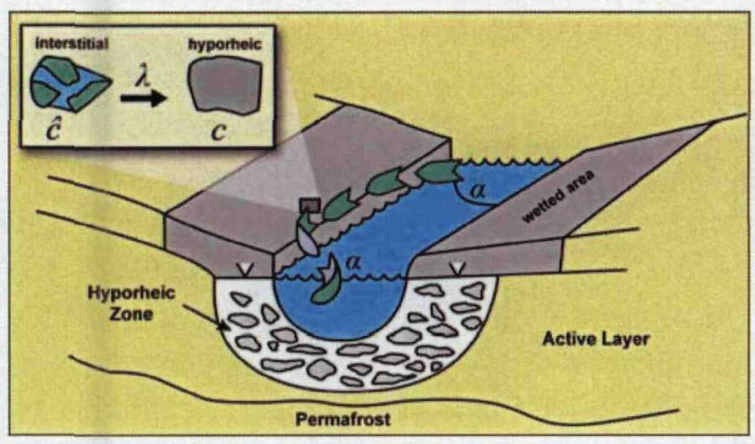

Figure 5. Sub-streambed (hyporheic) weathering of silicate minerals by pressuredriven flows in Antarctic streams (after Wurtsbaugh et al. 2003).

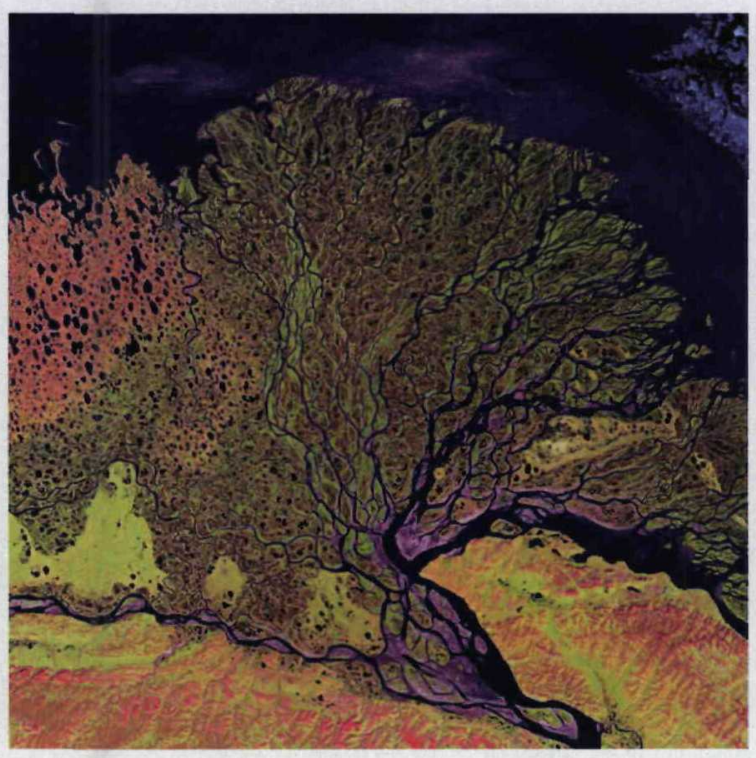

Figure 6. Large rivers such as this collect water from Eurasia and northern North America, and discharge it into the Arctic seas. (Reproduced from Stocker TF and CC Raible. 2005.

"Climate change: Water cycle shifts gear." Nature 434:830-831 with permission from Nature and the authors. Copyright 2005 Nature Publishing Group.)

physical mixing, this interface zone is extremely difficult to model mathematically and is frequently omitted from open ocean circulation models. Lack of understanding of this interfacial region makes it hard to determine the 
biogeochemical fate of nutrients and other constituents discharged into coastal waters.

At the microscale, the water-solid and water-air interfaces are regions where organisms accumulate and reaction density is high. There is a critical need to understand the controls on, and ramifications of, short- and long-term biogeochemical kinetic processes at this scale and their influence on cycling at broader scales. The structure, chemistry, and dynamics of the mineral-microbe-water interface (from single cells to biofilms) are not well understood. Understanding the interface between ecosystems is equally important. This includes the links between terrestrial, wetland, and aquatic systems and the interfaces between different aquatic systems (e.g., rivers to lakes and coastal ocean). On a reach to regional scale, this includes water's role in the transport of terrestrially derived material to aquatic systems and the land margin environment where this flux occurs. This includes wetlands, estuaries, near-shore coastal zones, hyporheic zones, riparian corridors, and riverine systems.

Each of these systems tends to have its own research community and tradition. Yet pollutants, nutrients, and organisms readily cross these system boundaries. Scientific advances in the coupling of hydrology, ecology, biology, chemistry, and geology will make important contributions to meeting water quality and quantity demands while addressing a number of other applied environmental issues, such as contaminant/pathogen fate and transport, natural attenuation of contamination, water quality, sustainable soil fertility, and the emergence and spread of waterborne diseases and non-native species.

Each of these systems tends to have its own research community and tradition. Yet pollutants, nutrients, and organisms readily cross these system boundaries.

\section{Theme 2: Coupling Human and Natural Systems Across Spatial and Temporal Scales}

There is also a need to integrate human systems into the study of aquatic systems and the water cycle. Humans have traditionally settled in proximity to water resources and subsequently modified the hydrology, chemistry, and biology of these systems (Wurtsbaugh et al. 2003). The resulting changes have impacted both the quality and quantity of water resources.

Throughout history, ubiquitous feedback between human and natural aquatic systems has profoundly affected both the structure of social institutions and the integrity of natural ecosystems. Enabled by advances in technology and engineering, increasing human demand for water is intensifying the cycling of water between human and natural systems. The amount of water that can be extracted and the distance it can be transported are increasing. Control structures allow development in previously inhabitable areas (e.g., the Everglades). Industrial processes yield a continually diversifying waste stream, now including pharmaceuticals with unknown impacts on aquatic biota - and humans.

As the human population grows and disperses, land use/cover changes will further alter evapotranspiration, runoff, groundwater recharge, and other hydrologic processes. With varying degrees of effectiveness, technological and engineering advances are in turn employed to mitigate the impacts of these anthropogenic changes and maintain the integrity of aquatic systems for biota and human use. Providing adequate water quantity and quality for human consumption while maintaining the integrity of aquatic ecosystems will require understanding of the natural and human structural components of aquatic systems and the interactions between them with particular emphasis on critical feedback loops that drive their evolution (see lecture by Dahm in Appendix C). 
Water quality and water quantity are traditionally approached as two separate issues. However, with the interaction between human and aquatic systems intensifying, issues of water quality and quantity are increasingly linked. In addition to modifications in water flux, the hydrologic changes resulting from human activities significantly alter distribution and delivery of nutrients, sediments, and pollutants to and through aquatic systems. This, in turn, affects the biotic communities found within these systems. Quantifying the impact of these changes to biotic communities and overall system integrity depends upon improved understanding of the coupled physical-biological cycling previously discussed. This understanding is essential for the development of integrated approaches to water resource management that address the concerns for water quantity and quality in tandem.

Microscale and fast processes regulate the overall chemistry of groundwater and surface water, and improved understanding of these processes is needed to predict and modify, if needed, the impact of increasing anthropogenic chemical pressures on the hydrosphere and biosphere. We need to understand the linkage of microscale mechanisms with their macroscale manifestation. It is important that we understand when it is acceptable to average small-scale processes and when we must account for small-scale heterogeneities.

It is also apparent that the practice of "averaging" across watersheds to address regional concerns will not always work. Comprehensive field and lab research coupled to new scale-sensitive mechanistic models will provide important insights on how chemical and microbiologic processes are manifested at the decameter to kilometer scale, and how largerscale phenomena (e.g., rainfall events, physical/geologic heterogeneities) control the rates and progress of molecular-scale processes.

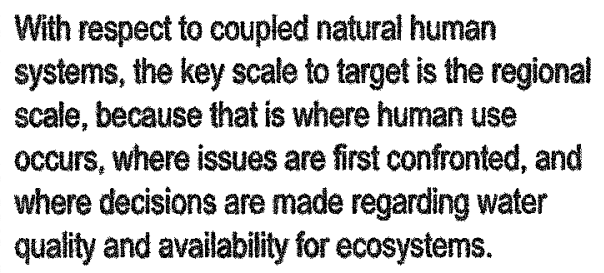

With respect to coupled natural human systems, the key scale to target is the regional scale. This is the scale where human use occurs, where issues are first confronted, and where decisions are made regarding water quality and availability for ecosystems. The regional scale is also the natural organizing scale by which water and human/environment interactions connect to the global scale.

Geomorphologically, watersheds are networks of river reaches. However, physical and biological processes are likely not a simple sum of processes occurring in those river reaches (i.e., the whole is greater than the sum of its parts). Cross-scale investigations will lead to better understanding of coupled processes and cycles in watersheds.

\section{Theme 3: Improving Prediction Through Advancements in Theory and Observation}

Predictive science is the key to forecasting how coupled human and natural systems respond to natural variability and to human modifications of the water cycle, the landscape, and the atmosphere. Predictive models are used to convey and compare potential futures for decision makers. Their accuracy depends fundamentally upon our mechanistic understanding of the environment and our ability to quantify essential environmental processes - despite inherent unknowns in our knowledge of natural system characteristics and behaviors and the approximation of these systems using mathematical simplifications (i.e., models). The scientific advances discussed will enable the development and improvement of 
predictive models to support sound decision making with respect to water resources.

Aquatic and hydrologic sciences are limited by a lack of broadly applicable concepts and theories. The current knowledge base is built largely upon observational and/or short-term investigations that often yield understanding only of the particular system under study. As highlighted in the workshop lecture by George Hornberger (Appendix $\mathrm{C}$ ), the research community needs to move beyond case-by-case understanding and place a greater emphasis on the development of theories and concepts that are transferable among systems and across times. Strong coupling of theory and modeling with experimental studies is essential to developing a mechanistic understanding of environmental processes. The fluid environment presents formidable challenges to both theory and experimentation.

Although there are exceptions (e.g., Canada's Experimental Lakes Area and the Hubbard Brook Long-Term Ecological Research [LTER] site), the ability to conduct whole-system experiments is particularly limiting. The community must maximize the benefits from the locations where whole-system experimentation can be done and systematically link the system-level knowledge gained with observational and experimental approaches in other systems to derive greater theoretical understanding.

Heterogeneity of processes and properties across the landscape is both a key attribute and a key challenge to theory development. A single observatory or experimental site cannot by itself capture the rich diversity of characteristics (e.g., geology, topography, vegetation, land use). To quantify heterogeneity and natural variability and allow the development of robust and transferable theories, observations representing a range of conditions are needed to broaden the context of experimental studies.
Through data integration, synthesis, and modeling activities, existing and new observational datasets can be used to test hypotheses and concepts and improve our prediclive capacity.

There is a vast and under-used record of environmental observations that can and should be synthesized for this purpose. Although they are valuable and cost-effective. legacy datasets have limitations. They are both difficult to access, a topic discussed below, and variable in quality. Because they were collected for myriad purposes and sometimes by vastly different techniques, data gaps remain and uncertainties exist. Consequently, systematic design and implementation of additional observing networks is required. Through data integration, synthesis, and modeling activities, existing and new observational datasets can be used to test hypotheses and concepts and improve our predictive capacity.

Theory and conceptual understanding provide the basic framework upon which quantitative models are constructed. Models can be used retrospectively to test conceptual understanding of environmental processes. First we must construct a model that reliably reproduces what we have already observed. With this accomplished and with sufficient mechanistic understanding, predictive models can then be constructed that forecast future conditions. Within the bounds of uncertainty, predictive models and their forecasts of future scenarios are used to inform policy and decision makers at all levels. For example, engineered facilities for control, use, and quality of water resources (reservoirs, canals, irrigation systems, diversions, treatment plants, etc.) are designed and operated using models. Where models are naive, as they often are, designs and operating rules are inefficient and may even be hazardous. The common practice is to assume a stationary climate, in which the future is presumed from the statistics of the past. This assumption is 
clearly false, and models must be updated to include current understanding of climate variability and change.

As previously noted, humans alter the water cycle at all scales. In developed countries, and particularly in the United States, engineered and managed rivers are the norm, not the exception. Consequently, predictive models must explicitly and quantitatively include human systems (social, economic, and political) if they are to be accurate and effective tools for decision-making. Models that forecast responses to human modifications of the water cycle, the landscape, and the atmosphere need to include feedbacks to the human system to yield useful results. For example, understanding the science of groundwater recharge without understanding the effects of urban and suburban development and the response of people to changes in water availability does not contribute to the long-term viability of aquifers underlying southwestern cities.

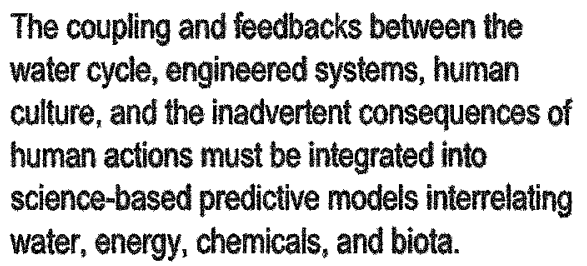

Ethical considerations of water use (e.g., development and decision-making associated with uneven distribution of water resources, or the uneven quality of water supplies) further link the human dimension to the water cycle, and in particular to engineered facilities for water supply and policy decisions regarding water quality and demand. The coupling and feedbacks between the water cycle, engineered systems, human culture, and the inadvertent consequences of human actions must be integrated into sciencebased predictive models interrelating water, energy, chemicals, and biota. Such models would be powerful tools for planning and engineering and balancing human needs and desires with environmental stewardship and restoration.
One of the biggest challenges in using predictive models to inform decision makers and the public at large is the concept of uncertainty. Uncertainty underlies all modeling studies and needs to be explicitly and consistently recognized, quantified, and reduced through further study. Uncertainty factors into modeling in several ways. Model parameters (properties, as well as boundary and initial conditions) have intrinsic uncertainty associated with their values resulting from measurement errors and spatial and temporal variability. Cumulative effects of this type of uncertainty can be probed mathematically and can be quantified by sensitivity analysis.

The conceptual model structure (scales, algorithms, processes, and couplings) is also almost always uncertain and can significantly bias predictions. This uncertainty is seldom addressed, although scenario analysis is sometimes used. Recently, watershed hydrologists have explored the concept of "equifinality" (Beven 2001) to allow a large suite of equally acceptable conceptual models, without necessar-ily showing preference for any particular subset of these models.

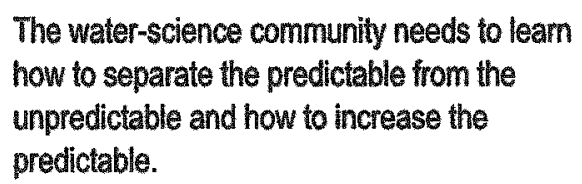

There is also the effect of uncertainties on the model results, the predictions, and the responses of the external users to these predicted changes. Even unbiased parameter errors, propagating though a nonlinear model, can bias the outcome and inversely impact engineering or policy decisions. The coupled interdisciplinary models of whole systems, emphasized above, are complex and highly nonlinear. These models can exhibit chaotic behavior in which the model is sensitive to even small changes in parameters (especially initial or boundary conditions). Atmospheric science evolved the concept of "predictability" to measure the sensitivity of 
predictions to these perturbations and score forecasters (models and people) by their ability to make accurate predictions in the face of this behavior ("limits to prediction"). The waterscience community can gain insights from this example on how to separate the predictable from the unpredictable and increase the predictable.

All of these concepts must be brought together to improve existing uncertainty approaches, to build new ones to maturity, and to incorporate all of them into predictive models used for water-science research or application.

Decreasing model uncertainty will evolve by systematically 1) improving process understanding, 2) identifying appropriate spatial and temporal scales and processes and couplings for the system under study, 3 ) reducing bias in conceptual models, 4) assessing measurement and parameter sensitivities and uncertainties, 5) continuing experimentation and systematic observation, and 6) recognizing that more than one model, modeling approach, or modeling output may best couple scientific information to real-world applications.

\section{New Approaches}

The reductionist approach that characterized the bulk of scientific research in the $20^{\text {th }}$ Century is clearly inadequate for addressing water as a complex, nonlinear problem strongly impacted by natural and human forcing functions that are both variable and interacting. Rather, a qualitatively different approach of multidisciplinary systems science is required for rapid progress in characterizing the complexity of such a problem in a usefully predictive manner, as illustrated in Figure 7. New tools and new approaches are required to resolve these critical interdisciplinary scientific challenges. It is also essential to break down barriers, particularly among disciplines and within institutions.

This arena of the small and fast is an important part of the water challenge, and we describe below the teaming, observational tools, data curation and modeling, and infrastructure needs identified by workshop participants as critically important to achieving progress in establishing a

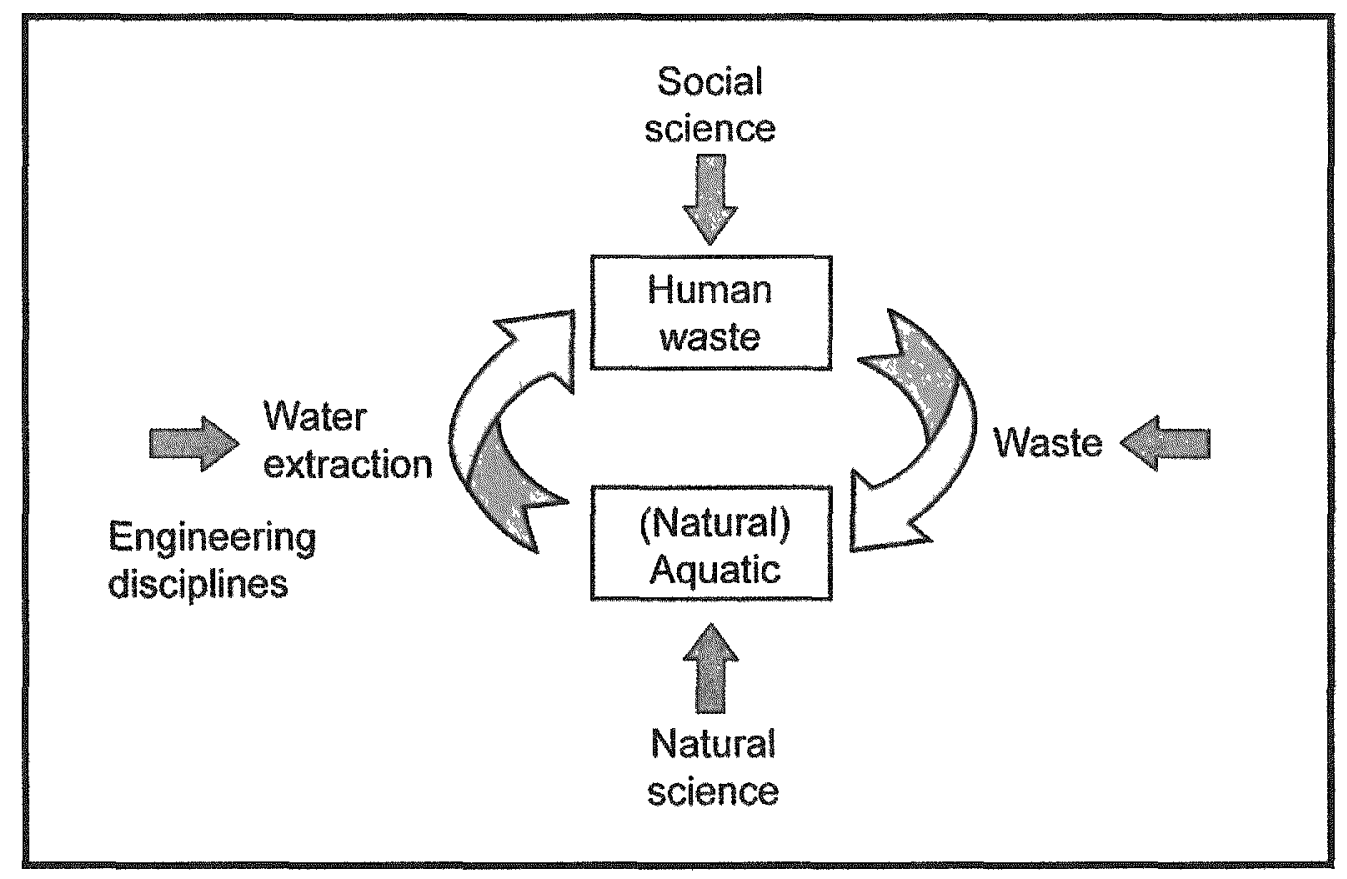

Figure 7. Multidisciplinary approach for addressing water issues. 
reliable framework for water as a complex system. We also describe briefly the educational challenge of preparing the future workforce to address complex socio-environmental problems of this type.

\section{Teaming}

DOE's national laboratories practice multiinstitutional teaming, in which teams of investigators come together to focus on major problems. Rewards and recognition for team achievement in ways at least as significant as those for individual achievement are essential characteristics of this systems science approach. National user facilities are a second characteristic of national laboratories relevant to tackling complex problems such as water, as they provide advanced instrumentation, support staff, and computation resources that comprise a valuable asset for investigating nano and microscale phenomena.

\section{Observing Systems, Sensors, Data, and Infrastructure}

The capacity to address the science themes posed above will require carefully planned interdisciplinary experiments as well as improvements in observing capacity. Tackling theory advancement, heterogeneity, and natural variability will require new experimental designs and more observational data. Progress on the challenges at the microscale would be greatly enhanced by new instrumentation and sensors for quantifying environmental variables. Also needed are field sites, laboratories, and other facilities where investigators of diverse backgrounds can collaborate to develop a systems-level understanding of coupled processes across different spatial and temporal scales.
Tackling theory advancement, heterogeneity, and natural variability will require new experimental designs and more observational data.

\section{Observing Systems}

Long-term, large-scale observational data are essential to answering many water science questions. Many federal agencies are already involved with long-term data collection (e.g., U.S. Geological Survey [USGS] hydrologic data, National Aeronautics and Space Agency [NASA] satellite data, National Oceanic and Atmospheric Administration [NOAA] climate data, and NSF ecological data). Such datasets provide an important baseline of understanding. However, because these efforts are uncoordinated and collected at different spatial and temporal scales, integration is difficult, and important gaps in knowledge persist. Driven by government monitoring needs, integrated observing systems and observatories, such as the Global Earth Observation System of Systems (GEOSS), are being developed that recognize and embody the coupled and complex nature of environmental systems at all scales.

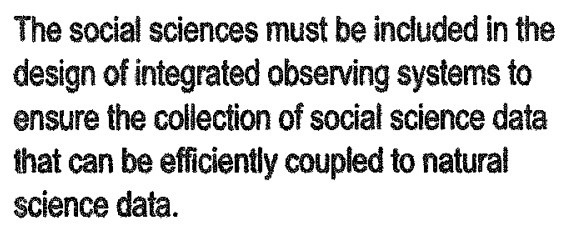

This research community should engage in and shape the design and implementation of observing systems and networks to ensure that the resulting datasets can be used effectively to answer interdisciplinary research questions. Social scientists should be included in the design 
of integrated observing systems to ensure the collection of social science data that can be efficiently coupled to natural science data. Social scientists also must be involved in interpreting these data, and then translating the data for the public and federal agencies to show the application to real-world problems.

\section{Sensors and Tools}

Some of the research gaps identified above result from limitations in currently available sensors and tools. Advances in sensor technology are needed for appropriate analytes and parameters to monitor in situ environmental responses in real-time over the spatial domain of interest for rigorous cause-and-effect studies. Sensors and sensor networks should be developed and deployed to collect key environmental data needed to understand critical processes over appropriate spatial and temporal scales. Biofouling and adequate power supplies for remote deployment are current challenges to in situ environmental sensors. The research community also needs to be educated about these sensors and tools so they can appropriately use the datasets generated by them.

Advances in tools and instrumentation are needed in addition to improvements in sensor technology. At the smaller spatial scales these tools include microscopy that requires no or minimal sample manipulation and more sensitive molecular spectroscopies for characterizing hydrated environmental samples and spatially resolved and compound-specific measurement and speciation techniques for the nano and microscales. Genomics and proteomics methods should be extended to complex, poorly culturable microbial communities. Larger-scale research needs include ground- and space-based observatories and spatially and temporally coherent observational campaigns and historical reconstruction studies (e.g., paleoreconstruction of drought).

\section{Data}

Improved access to and coordination of databases will provide new opportunities for interdisciplinary synthesis activities, integrated modeling and theoretical developments. The environmental data currently collected by individual investigators, government agencies, and other institutions are an invaluable resource. However, accessibility is widely variable, and much is underused or lost as a result of current approaches to data management and archival. For example, file formats and magnetic tape technology of the past few decades are no longer compatible with today's computers. With current approaches, it will be nearly impossible to reconstruct environmental records decades from now.

Our capacity to address some of the complex. interdisciplinary research questions posed above. including documentation of environmental changes, depends upon the availability of highquality data of known pedigree over a range of spatial and temporal scales. There is a need to integrate databases from disparate disciplines and establish open-access protocols and a mechanism for preserving data over time. Coordination and implementation of metadata standards are also essential to success.

Creation of an open public database for a broad spectrum of data where all researchers can deposit and retrieve environmental data that meet a predetermined standard of quality is a plausible solution. Ownership of data is an issue that must be solved for such a database to be widely available and truly useful. Social science data should be included to enhance our ability to incorporate the human dimension into research questions.

Interoperability of databases, curation of data. development of network access techniques, and deployment of collaboratory tools are recognized as critical components of the cyber infrastructure needed to enable the water 
research community to carry out the types of research envisioned here. The rapid advancement in computational tools and methodology for dealing with enormous distributed datasets demands a focused effort on visualization of measurements and the results of predictions. The connection of human intellect to high-dimensionality metadata is only possible through advanced visualization tools, many of which have yet to be created. These needs and challenges across scientific disciplines have been explicitly recognized in previous workshops (Futrell et al. 2003).

\section{Laboratory Infrastructure}

There is a need for readily accessible, moderately sophisticated laboratory facilities available for dedicated use in water science research and development. In many cases, this kind of infrastructure can be shared with other scientific disciplines, particularly those with an environmental sciences theme. Such facilities must be operated and maintained by personnel familiar with the nuances of water research. This need is motivated in part by the inability to access existing facilities used in other disciplines because of the potential of contamination by "dirty" water samples.

DOE synchrotron light sources and other user facilities such as PNNL's EMSL enable state-ofthe-science research in more molecular aspects of environmental biogeochemistry such as chemical and biological speciation, and these facilities can support important new scientific advances in this field. However, uses and applications of these sophisticated instrumental facilities are not widely known to the diverse water research communities.

More aggressive outreach, education, and knowledge sharing about and by these facilities to the scientific community are needed to maximize their use and scientific impact. Moreover, new laboratory-based user facilities of as-yet undefined scope and theme could greatly advance this field of research if appropriately and objectively conceptualized. Advances in the biomedical sciences will be important in water science research, along with sensor technologies from chemistry and material science areas.

\section{Overcoming Educational and Institutional Barriers}

The problems that will be addressed in this century are no longer amenable to reductionist approaches applied within the rigid disciplinary boundaries. Hydrologists alone will not be able to solve society's current and pending water problems. Physics, chemistry, biology, geology, hydrology, limnology, mathematics, computer science, climatology, oceanography-indeed all of the physical and life science disciplinesmust contribute to the solution of water as a complex problem. Further, the communication, interpretation, and implementation of water science calls for early and continuous engagement of the social sciences in water research. For these reasons and others, interdisciplinary science must continue to be nurtured and supported by changes in attitudes, education, and institutional structures and practices.

\section{Education}

The scientific advances needed in water research require dedicated, highly collaborative multidisciplinary teams that actively seek a fundamental but more holistic understanding of environmental biogeochemical and hydrologic processes. However, strong infrastructure and technically advanced research tools will accomplish little if the next generation of scientists is not there to use them. This is a compelling reason for increased support for interdisciplinary training of students. We need to rethink education models in light of national needs for an interdisciplinary work force. This training should also encourage and enable productive communication with and mutual 
understanding among the public at large, policymakers, and scientists.

Two central themes will define the next generation of interdisciplinary scientists: one is a redefining of traditional disciplines; the other is collaboration. It is irrational to expect any individual to master all aspects of complex environmental science. Thus, some students will become "discipline plus" scholars who have a core expertise in a traditional discipline with adequate expertise across disciplines to be an effective collaborative player, while others will train in new mixes of skills to become more fully integrated "interdisciplinary" scholars.

This latter model recognizes that the current boundaries of disciplines are a human convention, and that solid scholars can have areas of core expertise that overlap those traditional categories. New education models for undergraduate and graduate students should explicitly include a systems-level approach that cuts across disciplinary categories to encourage the development of both types of scholars.

New education models for undergraduate and graduate students should explicitly include a systems-level approach that cuts across disciplinary categories.

Professional practice, including early participation in professional conferences and cyberenabled science, will provide the next generation of environmental scientists with the context for their research and provide opportunities for interactions outside their lab and discipline. Academic centers can adapt parts of the model that engineering education, industrial research centers, and national laboratories have used for years. Internships and co-op programs are great ways for students to get hands-on experiences in fields outside their own specialty. For environmental science students at all levels there is a general need for more field training.
Professional societies can offer crossdisciplinary workshop sessions and similar opportunities to foster interdisciplinarity. A new think tank (incubator) completely devoted to interdisciplinary environmental research could serve as a useful model. In such an incubator, investigators get together to discuss an interdisciplinary environmental problem, learn each other's language, and then formulate a project (e.g., National Center for Ecological Analysis and Synthesis).

\section{Institutional}

Traditional academic structures have not been well suited for interdisciplinary research, education, rewards, group activity, etc. If you are part of an interdisciplinary team, for example, you may be the fifth author, while in your specialty you may be the lead author. This can be particularly problematic for tenure track faculty. This issue has been resolved by scientific fields where collaboration is the norm rather than the exception; for example, for scholars who depend on very large accelerators or astronomical observatories conducting research. These practices need to be expanded to include multidisciplinary efforts generally.

\section{Integrating Science and Policy}

It is widely recognized that science is done for the benefit of society. Nevertheless, a cultural gap separates the practitioners of science from decision makers that use science for the public good. This is a barrier to incorporating best scientific knowledge into decision-making around water as a specific complex societal problem. These issues are exacerbated by the realization that water agencies and the public they serve tend to act or react locally, even though many water problems can take on regional or global dimensions. To close gaps between state of the science and state of the practice in addressing water resource issues will require outreach to increase connectivity between scientists, decision makers, stakeholders, and the public at large. To that end, a 
more galvanized scientific community that can articulate an overarching water research agenda would be beneficial in interacting with federal, state, and local governments; local water agencies; educators; and the public.

\section{Developing Science to Inform Decision- Making, Policy, and Management}

Water science should be expanded to recognize explicitly a broader set of societal and ecosystem needs. Understanding the connections and feedbacks between ecosystem characteristics and human needs will identify necessary tradeoffs inherent in water policies that must accomplish multiple objectives. Rational decisions based on informed understanding of consequences will minimize adverse impact on human and nonhuman components of the ecosystem.

New decision-making tools are needed that examine systems holistically, capture the risk of negative consequences, quantify uncertainty, and discriminate between big and small problems. Decision-making tools must include methods for accurately valuing the ecosystem services provided by watershed processes and incorporating these valuations into decisionmaking. Improved communication will facilitate a better understanding of the influence of ecosystem characteristics on human health and well being.

\section{Conclusions}

Understanding water as a coupled human-natural system requires imaginative, interdisciplinary, and integrative research that transcends scales of time and space never before realistically addressed. The rapid and continuing development of measurement tools and sensors along with ever-expanding computational speed and capacity for modeling and simulation provide the basis for the challenge to achieve a predictive understanding of an exceedingly complex system.
Collaboration among scientists who use different conceptual and diagnostic approaches is the key to rapid progress in the field. Water quality and quantity have typically been managed at local and regional jurisdictions, and the global impact of human development has only recently been recognized. Cooperation and collaboration is needed among a number of agencies and institutions within the United States and among nations that lack a tradition of working together.

To enable the full understanding of the interaction of water with the environment demands

- New scientific understanding at the molecular and biological scale

- Improved understanding of transport and environmental exchange

- Understanding of its interaction with the natural and developed landscape that drives transpiration, evaporation, precipitation, and subsurface exchange

- Understanding of the impact of climate change on all these processes.

Continuing research by existing groups and disciplines is needed, but the overarching challenge of achieving predictive understanding can only be achieved by cross-disciplinary and interdisciplinary efforts that the workshop delineated at a high level. These are diagrammed in Figure 8, which is adapted from Clifford Dahm's lecture at the workshop.

The central feature at the top of this illustration is a section of the river reach that may be considered the fundamental unit of a model for characterizing interactions present in a coupled complex water system. As described in Dahm's lecture, this unit must include wellcharacterized, measurement-based descriptions of the coupling of the riparian zone with the river channel and with the hillside, terraces, percolation of underground water, local vegetation, stream runoff, and precipitation. In other words, this unit is scientifically described 


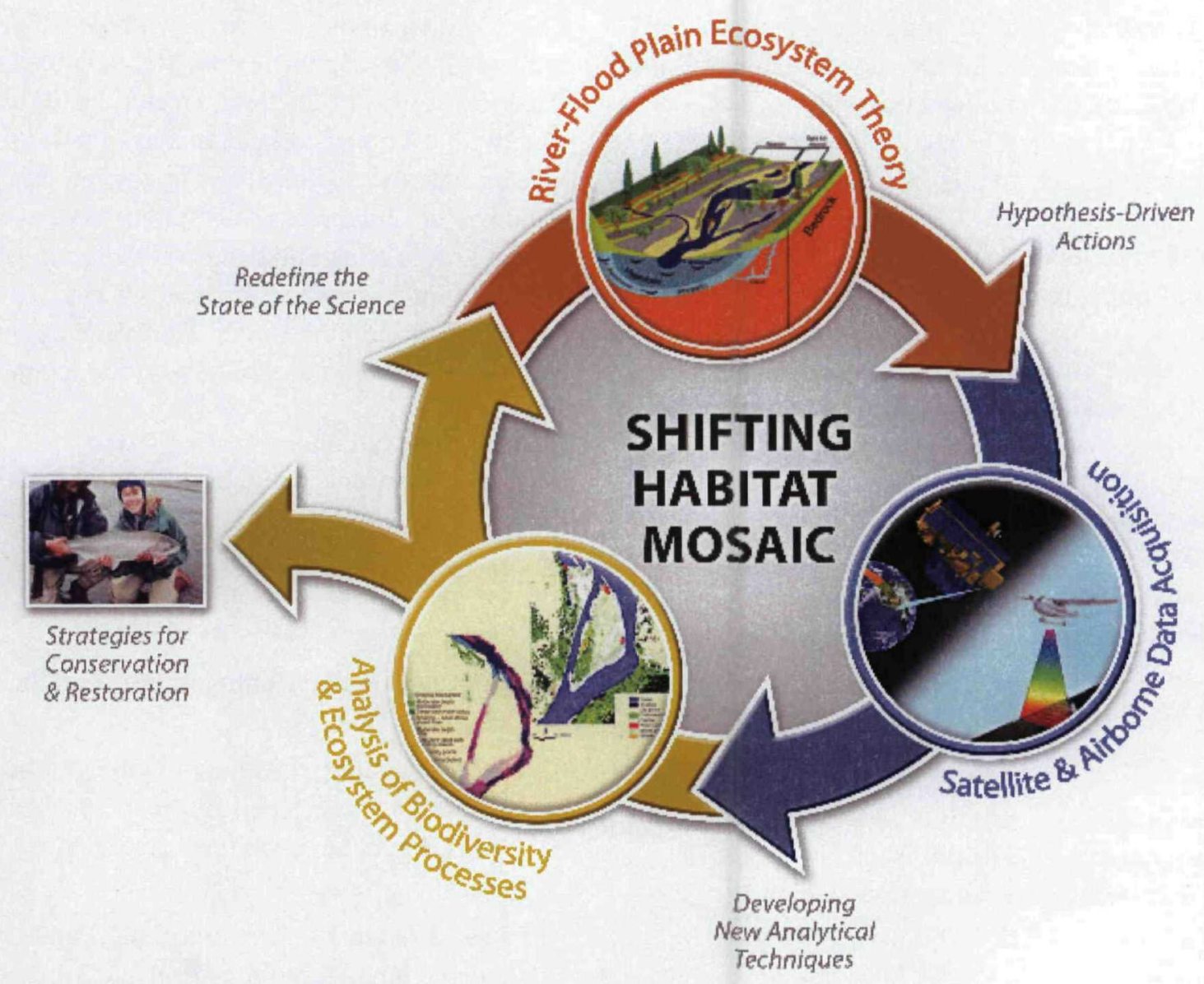

Figure 8. Linking ecosystem theory and new technologies for biodiversity, water quantity, and water quality in a variable and changing climate.

by the minimum data that characterize this section of the river reach. This unit will be described in different ways when it involves urban areas, proximity to air and water pollution sources, and is near either the headwaters or the mouth of the river.

It is also strongly dependant on season, temperature, and climate; its characterization involves many measurements over time along with theoretical modeling of the influence of all coupling terms. This starting point leads to hypotheses, further measurements, and interpretation that improve the model. New analytical techniques, biodiversity, and coupled chemical and biological interactions are key parts of analysis and synthesis. This leads to strategies for conservation and restoration to maintain and improve environmental stewardship that, in turn, lead to redefining the science of this complex system.

Extending this concept in time and space engages all the disciplines represented at the workshop - chemists, biologists, biogeochemists, ecologists, hydrologists, theorists, engineers, and modelers. Their individual and especially their collective interactions are essential to understand the forcings and feedbacks inherent to highly coupled, nonlinear complex systems. Their interdisciplinary product will enable us to understand and predict system responses to climate variability, land use change, and land cultivation. It is essential that we grapple with these problems at a fundamental level through 
advancing the science of complex and dynamic environmental systems. Fundamental science must move beyond the reductionist approach of defined, small, homogeneous, and wellcontrolled systems.

Virtually every water system in developed countries and all river systems in the Western United States are managed by extensive dam systems that have profoundly altered the natural hydrology. The consequences of this are poorly understood, at best. Major usages of water for agriculture and energy production strain limited resources and have major economic consequences that are also poorly understood. Socioeconomics is an increasingly important issue, and social scientists must be engaged as we move from greater understanding toward development of public policy about water as a complex system. Though this was beyond the scope of this particular workshop, we nevertheless must call attention to the importance of these larger issues.

Our workshop brought together a significant cross-section of the broader community concerned with water as a complex environmental issue. We identified several areas deserving special emphasis by the federal agencies most concerned with fundamental research on water, particularly the DOE and NSF, as follows:

- Research efforts specifically directed at the coupling of cycles and processes for chemical-biological-hydrologic phenomena at the nano to microscale, paying particular attention to interfaces.

- Multidisciplinary research on water is inherently multiscale as well as multidisciplinary, and targeted research on linking water complexity at multiple scales is needed, particularly linking microscale phenomena to the watershed scale and the regional scale where ecosystems and human needs most strongly intersect water resource management.

- Observatories operating at many scales, as well as sensors and infrastructure, are essential to understanding water as a complex system. Protocol for the resulting data and its access and archival must also be addressed.

- Theoretical models based on hypotheses and refined by experiment are essential to developing theory and predictive understanding. Testing of hypotheses and definition of uncertainties in predictions at all scales are needed.

- Workforce and education are critically important issues. A new type of scientist, grounded in a discipline in depth but equally well trained and motivated to address complex problems of great importance to society, is as important as developing the tools and ideas described in our report.

The emphasis of our workshop was the gathering together of experts from the range of disciplines and specialties that could discuss the broad scope of water as a complex system ranging from molecular scale to continental scale, including climate as a forcing function. The breadth of our coverage of the topic prevented our discussion in depth of the areas for research outlined in our report. It is our assumption that future workshops will focus attention on a more detailed research agenda to address the priorities we have identified. 



\title{
Appendix A - Workshop Agenda
}

\author{
Thursday, September 16, 2004
}

$7: 30-8: 00$

8:00-8:30

$8: 30-9: 15$

$9: 15-9: 45$

9:45-10:00

$10: 00-10: 30$

$10: 30-10: 45$

$10: 45-11: 00$

$11: 00-11: 30$

$11: 30-11: 45$

$11: 45-12: 00$

$12: 00-1: 00$

$1: 00-1: 30$

$1: 30-2: 00$

$2: 00-2: 15$
Bus arrives to pick up visitors at hotel(s) and drives to EMSL

Refreshments and pick up workshop materials (EMSL 1075/1077)

Welcome, schedule, logistics, and charge by Jean Futrell, PNNL; Introductory remarks by telephone by Teresa Fryberger, Office of Science \& Technology Policy; Margaret Leinen, National Science Foundation (NSF); and David Skole, Chair of NSF, Advisory Committee for Environmental Research \& Education (EMSL Auditorium)

"Water, Interfaces, and Environmental Complexity at the Microscale" by Trish Holden, Associate Professor of Environmental Microbiology (University of California at Santa Barbara); introduced by Josh Schimel (EMSL Auditorium)

Discussion (EMSL Auditorium)

"A River Runs Through It: Of Reaches, Riparian Zones, and Recharge" by Clifford Dahm, Professor of Biology (University of New Mexico); introduced by Jean Futrell (EMSL Auditorium)

Discussion (EMSL Auditorium)

Break

"Are Large Watersheds More Complex Than Small Watersheds?" by George Hornberger, Ernest H. Ern Professor, Department of Environmental Sciences (University of Virginia); introduced by John Wilson (EMSL Auditorium)

Discussion (EMSL Auditorium)

Introduction and Charge to Breakout \#1 Sessions (Science and Technology) by Jean Futrell (EMSL Auditorium)

- Nano/microbial Scale (Lead: John Zachara)

- Reach Scale (Lead: Peggy Ostrom)

- Watershed Scale (Lead: Dan Childers)

- Regional scale (Lead: Anna Barros)

Lunch (all); visitors pick up security badges at EMSL front desk if not done earlier (EMSL 1075/1077)

"Water and Environment at the Ocean Interface" by John Melack. Professor of Biological Sciences (University of California at Santa Barbara); introduced by Josh Schimel (EMSL Auditorium)

"Submarine Groundwater Discharge: A Lesser-Known Route for Material Exchange Across Land/Sea Margins" by Peter Swarzenski, Chemical Oceanographer (United States Geological Survey); introduced by Ellen Kabat-Lensch (EMSL Auditorium)

Discussion for Talks by Melack and Swarzenski (EMSL Auditorium) 
Thursday, September 16, 2004

$\begin{array}{ll}\text { 2:15-2:30 } & \text { Break } \\ \text { 2:30-4:30 } & \text { Breakout \#1 Sessions (EMSL 1075, 1077, 1185, and Board Room) } \\ \text { 4:30-6:00 } & \text { Adjourn; bus returns visitors to hotel(s). Visitors taken to boat. } \\ \text { 6:00-8:00 } & \text { Dinner cruise on Columbia River; lectures on river/watershed quality and use by } \\ & \text { Dennis Dauble (PNNL), Fish Biologist; and Roy Gephart (PNNL), } \\ & \text { Hydrogeologist } \\ \text { 8:00-8:30 } & \text { Participants needing transportation returned to hotel(s) } \\ 8: 30+ & \text { Breakout Session leaders and their facilitators finalize PowerPoint presentations } \\ & \text { for next morning (as needed) }\end{array}$

Friday, September 17, 2004

$\begin{array}{ll}\text { 7:30-8:00 } & \text { Bus arrives to pick up visitors at hotel(s) and drives to EMSL } \\ \text { 8:00-8:30 } & \text { Refreshments (EMSL 1075/1077) } \\ \text { 8:30-9:15 } & \text { "Climate Impacts on the Water Cycle" by Ruby Leung, Laboratory Fellow } \\ & \text { (PNNL); introduced by Roy Gephart (EMSL Auditorium) } \\ \text { 9:15-9:45 } & \text { Discussion (EMSL Auditorium) } \\ 9: 45-10: 00 & \text { Breakout \#1 Session leaders report findings and receive feedback from } \\ & \text { workshop participants (EMSL Auditorium) } \\ \text { 10:00-10:30 } & \text { Introduction and Charge to Breakout \#2 Session (Science and Society); address } \\ & \text { questions; John Wilson presiding (EMSL Auditorium) } \\ & \text { - Breaking Disciplinary Barriers (Lead: Ashanti Pyrtle) } \\ & \text { - Challenges in Providing Science for Society (Lead: John Wilson) } \\ & \text { - Linking Across Scales (Lead: Josh Schimel) } \\ & \text { - Impact on Water/Environmental of Coupled Human and Natural Systems } \\ 10: 30-10: 45 & \text { (Lead: David Skole) } \\ 10: 45-12: 00 & \text { Break } \\ 12: 00-1: 30 & \text { Breakout \#2 Sessions (EMSL 1075, 1077, 2185, and Board Room) } \\ 12: 30-1: 30 & \text { Lunch (all) (EMSL 1075/1077) } \\ 1: 30-2: 30 & \text { EMSL tour (optional) } \\ 2: 30-3: 30 & \text { Breakout \#2 Sessions (continued) (EMSL 1075, 1077, 2185, and Board Room) } \\ & \text { Breakout \#2 Session leaders report back findings to workshop participants, } \\ 3: 30-3: 45 & \text { receive feedback (EMSL Auditorium) }\end{array}$




\section{Friday, September 17, 2004}

$3: 45-5: 00$

Workshop wrap-up plenary discussion; follow on tasks; answer questions;

Organizing Committee moderating (EMSL Auditorium)

$5: 00$

Bus departs from EMSL for Dinner

$5: 30$

Conference Dinner at Hedges Winery

$8: 00$

Buses depart for hotels 



\title{
Appendix B - Workshop Participants
}

\author{
Workshop Committee
}

Jean Futrell, Pacific Northwest National Laboratory

Roy Gephart. Pacific Northwest National Laboratory

Ellen Kabat-Lensch, Eastern Iowa Community College District

Diane McKnight, University of Colorado

Ashanti Pyrtle, University of South Florida

Josh Schimel, University of California-Santa Barbara

Robyn Smyth, Knauss Marine Policy/NSF Fellow

David Skole, Michigan State University

John Wilson, New Mexico Institute of Mining and Technology

\section{Workshop Participants}

Jill Baron, National Renewable Energy Laboratory

Ana Barros, Duke University

Liz Blood, National Science Foundation, Biological Directorate

Gudmundur (Bo) Bodvarsson, Lawrence Berkeley National Laboratory

Beth Boyer, State University of New York, Syracuse

Patrick Brezonik, National Science Foundation, Engineering Directorate

Marge Cavanaugh, National Science Foundation, Geosciences Directorate

Dan Childers, Florida International University

Yo Chin, Ohio State University

Nick Cleseri, Rensselaer Polytechnic Institute

John Crimaldi, University of Colorado

Clifford Dahm, University of New Mexico

Dennis Dauble, Pacific Northwest National Laboratory

Ken Doxsee, National Science Foundation, Mathematical and Physical Sciences Directorate

Jim Fredrickson. Pacific Northwest National Laboratory

Lydia Gates, National Science Foundation, Geosciences Directorate

Janet Hering, Cal Tech

Trish Holden, University of California-Santa Barbara

Rick Hooper, Consortium for the Advancement of Hydrologic Sciences, Inc.

George Hornberger, University of Virginia

Steve Ingebritsen, U.S. Geological Survey

Upmanu Lall, Columbia University

Dennis Lettenmaier, University of Washington

Ruby Leung, Pacific Northwest National Laboratory

Sally MacIntyre, University of California-Santa Barbara

John Melack, University of California-Santa Barbara

Jason Neff, University of Colorado

Stacy Nelson, North Carolina State University

Peggy Ostrom, Michigan State University

Aaron Packman, Northwestern University 
Mike Paller, Savannah River National Laboratory

Carl Palmer, Idaho National Engineering and Environmental Laboratory

Tony Palumbo, Oak Ridge National Laboratory

Roy Rasmussen, National Center for Atmospheric Research

Carolyn Ruppel, National Science Foundation, Geosciences Directorate

Bridget Scanlon, University of Texas Austin

Durelle Scott, U.S. Geological Survey

Alison Smith, Kent State University

Walt Snyder, National Science Foundation, Geosciences Directorate

Everett Springer, Los Alamos National Laboratory

Peter Swarzenski, U.S. Geological Survey

Jennifer Tank, Notre Dame University

Andy Tompson, Lawrence Livermore National Laboratory

Sam Traina, University of California Merced

Enrique Vivoni, New Mexico Institute of Mining and Technology

Claire Welty, University of Maryland, Baltimore County

John Zachara, Pacific Northwest National Laboratory

Edie Zagona, University of California 


\section{Appendix C - Summaries of Keynote Lectures}

Water, Interfaces, and Environmental Complexity at the Nano to Microscales

Trish Holden, Associate Professor of Environmental Microbiology, University of California at

Santa Barbara

A River Runs Through It: Of Reaches, Riparian Zones, and Recharge

Clifford Dahm, Professor of Biologv, University of New Mexico

Are Large Watersheds More Complex Than Small Watersheds?

George Hornberger, Ernest H. Ern Professor, Department of Environmental Sciences, University of Virginia

Submarine Groundwater Discharge: A Lesser-Known Route for Material Exchange Across Land/Sea Margins

Peter Swarzenski, Chemical Oceanographer, United States Geological Survey

Climate Impacts on the Water Cycle

L. Ruby Leung, Laboratory Fellow, Pacific Northwest National Laboratory' 
Water, Interfaces, and Environmental Complexity at the Nano to Microscales

\author{
Trish Holden, Associate Professor of \\ Environmental Microbiology, University of \\ California at Santa Barbara
}

The subject of water at the small scale might be initially regarded as esoteric, but it is not. Instead, understanding small-scale aquatic science is central to the larger water and environmental issues. The ties to larger issues are many, but the research issues that "depend" on knowledge of nano- to microscale water are appropriately focused on water quality, availability, and use (National Research Council 2001). For all three we need to understand the physical, chemical, and microbial interactions governing contaminant fate and transport and the assimilation capacity of the environment and the time course of recovery. We need to understand the relationship of agricultural water use to climate, crop type, and water application rates; develop improved crops for more efficient water use; and optimize the economic return for the water used. And we need to understand the interrelationship between aquatic and terrestrial ecosystems to support watershed management.

Water's unique set of properties (e.g., high melting point, high boiling point, high latent heat of vaporization, low compressibility, the ability to be both solute and solvent, a solid form is less dense than liquid) arise from hydrogen bonding, which determines the structure of proteins, DNA, RNA, micelles, and biological membranes. But the tetrahedral coordination within the water molecule is what sets water apart from other hydrogen-bonding molecules.

Hydrophobic interactions and the hydrophobic effect both arise because of water's great affinity for itself. Hydrophobic interactions are central to micelle formation, many interfacial phenomena, and protein and biological membrane conformations. As one might imagine, by considering the structure of solid water, hydrogen bonding, and the hydrophobic effect, molecular water structuring is affected by and affects surface chemistry, interfacial physics, biological macromolecules, and microorganisms (bacteria, viruses, fungi) or cells or channels in higher organisms.

For this workshop, the contexts for water at the very small scale arise in natural and polluted environmental systems and in artificial, manufactured systems. The amount of water and the system it inhabits determine water's energetic state and its effects on biological processes. Water can be put into two general hydrologic contexts: unsaturated and saturated systems, both of which have specific scientific questions to be addressed, bulk water, an air/water interface, and a solid/water interface. A major scientific challenge is to understand how water and diffusion contribute to physical, chemical, and biological heterogeneity in saturated and unsaturated systems.

\section{The Saturated Environment}

A cross section of water includes the air/water, oil/water, and solid/water interfaces. Thus, we are concerned with the air/water interface; that is, the neuston, bulk water, and sediment pore waters.

It is safe to say that the neuston is highly understudied, particularly when it comes to microbial activity. The neuston is enriched in ampiphiles that are potential nutrient sources. What is the relative enrichment of microbes at the neuston? How can it withstand the stresses (mechanical shear, UV radiation) and by what mechanisms? What metabolic specialists exist here? If oil is present, are there super-degraders at the interface? What is the contribution of this interface to carbon and other nutrient cycling? What unique physiologies are expressed?

Figure $\mathrm{Cl}$ contains images of $P$ seudomonas aernginosa GFP-mutant expressing green fluorescent protein at the oil/water interface in a 

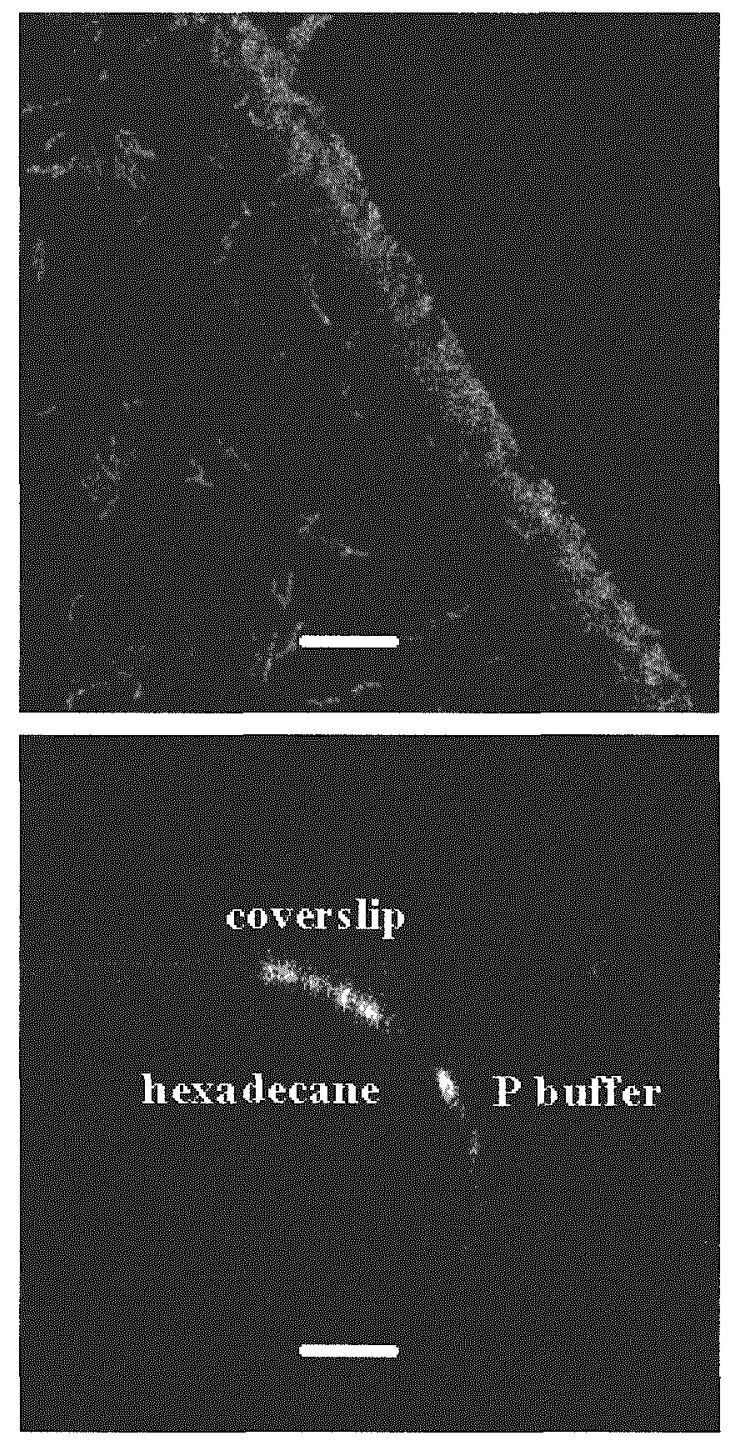

Figure C1. Pseudomonas aeruginosa. Top image is a plan view; bottom is a section that captures the radius of curvature at the oil/water interface (after Holden et al. 2002).

laboratory system. The GFP gene, in this situation, is being upregulated by a promoter for a bioemulsifying protein. It is interesting that gene transcription in this setting is only observable at the oil/water interface. We don't know if transcriptional activity is a prerequisite to adherence at the interface, or if adherence somehow stimulates transcription.
Bulk water contains micelles and flocs, which have special properties and participate in specific biogeochemical functions. Micelles are from ampiphilic (i.e., surfactant) molecules that self-assemble with hydrophilic groups oriented towards water and hydrophobic groups clustered towards themselves. Micelles and emulsions affect the pseudosolubility and thus the bioavailability of sparingly water-soluble substrates to microbes. Origins and roles of surfactants, emulsifiers, and micelles in nature are still unknown. If they are not just breakdown products, why would microorganisms make them, and what causes their "production"?

Flocs and the micro-mechanics of fluid flow and nutrient delivery at this scale are very important to understanding larval transport and floc formation, floc maintenance and growth and thus floc-associated cycling of nutrients. The organismal composition of flocs and the water flow within them and their polymeric composition are all contemporary questions. We need to know their polymer chemistry and the relation of floc chemistry to macroecology. Do benthic filter feeders in the water column actually recognize and respond to floc chemicals? Much work has been done, but more is needed to understand the delivery of substrates to and the removal of metabolites from these environments.

At solid/water interfaces in saturated systems, biofilms invariably form. Biofilms are now considered to be the predominant mode of growth for bacteria in any system; therefore, it is important to understand them better. Biofilms consist of cells anchored to a solid surface or to each other and embedded in hydrated expolymeric substances. Biofilm science has mostly developed from studying saturated flow cells, pipes and other surfaces in laboratory and natural saturated systems. There are at least three definitive books on the subject at this point in time (Bryers 2000, Characklis and Marshall 1990, Costerton and Lappin- 
Scott 1995). The operating paradigm in biofilm science is that biofilms consist of mushroomshaped colonies between (which water advects, nutrients are delivered and metabolites removed. But biofilms aren't always subjected to shear forces from flowing fluid, and thus the definition of biofilms being tied to this structure is very limiting.

In my group we distinguish between "saturated" biofilms grown under the typical flow-cell conditions and those grown in "unsaturated" conditions. The morphologies are very different between the two conditions, which makes sense given, in the latter case, the complete absence of fluid shear. Outstanding questions concern their physical structure, structure-function relationships, fundamental physiology, community-level organization and interactions, exopolymer chemistry and significance, eukaryotic and prokaryotic content, etc. Biofilm science is a revolution in microbiology, and such questions are at the heart of being able to understand and model microbially mediated nutrient cycling, including biodegradation of pollutants. Such questions are also essential to understanding disease processes and designing new disease therapies.

\section{Unsaturated System (porous media)}

Unsaturated environments are at least threephase: gas, water, and solid. Microorganisms can exist at the air/water interface, the solid/ water interface (i.e., as a sort of biofilm), and in bulk water. In unsaturated environments, we are concerned about the energetic state of water, or water potential, as well as water content. Water content is straightforward, either expressed volumetrically or gravimetrically. Water potential, on the other hand, manifests itself as a result of water's interactions with surfaces, in pores, or with solutes, the latter of which may pass through cell membranes or not.
The microbial response to low water potential originates in physiology and physics. One response was higher production of EPS polysaccharide (Roberson and Firestone 1992).

We don't know how prevalent this response is, if it is the outcome of a shifted nutrient status in favor of carbon, or if it is an intrinsic response to desiccation. We are only now learning about the genetic basis of matric water stress. We don't have a good description of how water molecules interact with microbes in a natural context to elicit a microbial response. Yet, the response manifests itself at much larger spatial scales and impact observed nutrient cycling.

Thus one can plot the rate of a microbially catalyzed reaction versus water potential and imagine a progression of effects during drying. The progression will be altered by whatever microbial survival strategies are invoked. It begins when wet porous media imposes an impediment to the diffusional resupply of gasphase nutrients (e.g., oxygen). As water-filled pores drain, diffusion becomes less restricted and rates improve for aerobic organisms; they may also be more adapted to slightly lower water potential. As water is removed further, thin films could become discontinuous. If so, nutrient imbalances may arise. If microbes are adhered to carbon particles, then the nutrient imbalance may favor higher $\mathrm{C} / \mathrm{N}$ ratios, for example, and this might favor increased EPS production when then changes water retention. Further desiccation may cause cracks in the EPS matrix and improve rates if nutrient shortcircuiting occurs.

Specific questions regarding microbial stress response to low water potential include:

- Is increased EPS production a stress response or a response to nutrient imbalance? 
- In liquid culture, bacteria are known to produce more polysaccharide as the initial $\mathrm{C} / \mathrm{N}$ abundance is raised. In unsaturated porous media, is this the mechanism or is it stress response?

- What are the specific genes that are transcribed?

- Why does water stress occur at such seemingly high relative humidities $(-1.5 \mathrm{MPa}$ is equivalent to around $98 \% \mathrm{rh})$ ?

- Are films thin, or structured over long distances in the complex environments of biofilms on surfaces?

The unsaturated microscale and the potential importance of EPS are worth further examination. Whether EPS increases because of water stress or toxicity, the matrix around microbes is a local diffusional barrier. Nutrients and metabolites must pass through it. One can model this local interplay of physics and physiology under steady-state conditions. We found that diffusion through this film was the limiting process in toluene biodegradation. The implication is that if EPS is hyperproduced in response to either water stress or toxicity, there will likely be a direct impact on the rate and modeling of microbially catalyzed reaction. These smallscale issues are potentially paramount to knowing pollutant fates.

These concerns about the microscale growth habit of microbes and their relation to water will likely be very important for surface soils, but they also may be important for deeper soils. EPS production is not widely embraced as a subsurface phenomenon. It has primarily been regarded as important in surface soils where nutrients abound. Yet there is some evidence that microbial sugars accumulate in the subsurface. We have preliminary evidence that extractable sugars decline significantly with depth, but that the ratio of microbial to plant sugars is pretty high even at $1 \mathrm{~m}$ depth. Are these sugars associated with the extracellular matrix? If the $\mathrm{C} / \mathrm{X}$ ratio is shifted to favor more C (as in hydrocarbon-polluted systems), does EPS increase? If so, what are the consequences for soil-water relations? This is important to consider, not only for polluted systems, but also for the scenario of plant propagated $\mathrm{C}$ from higher atmospheric $\mathrm{CO}_{2}$. Finally, what exactly is EPS and how is its chemistry important to its function? New data in the saturated biofilm literature and in my group don't support that EPS is only polysaccharide. What is EPS, and does it affect water and physiology differently, depending on its chemistry?

The overarching questions in this area relate to fundamentally understanding water stress in microbes and how stress response is modulated in the natural environment. This also extends to taking our understanding to the even smaller spatial or molecular scale of water and its interactions with microbes and their exopolymers. We need to understand the configuration of microbes (i.e., in EPS or not) in unsaturated environments and how this could influence our models of microbial processes. The penultimate question is then, under any given set of conditions, if the physics of the nano- to microscale or the physiology of organisms at that scale dictate what we observe biogeochemically at larger scales. This question is interesting and potentially important whether addressing basic microbial ecology such as cell-cell signaling or more applied concerns such as pollutant biodegradation.

There is a connection across these small- and larger-scale concerns. At a slightly larger scale than the nano- and microscale, the roles of water may be at the root of what we observe to be heterogeneity; that is, the heterogeneous distribution of organisms, and, perhaps relatedly, heterogeneous distribution of nutrients. My group in collaboration with others has analyzed scanning electron microscopy images of soil to try to quantify heterogeneity at the microscale. Soils are less complex with increasing depth. 
While we cannot attribute our observations of heterogeneity quantity to a mechanism, the amount of heterogeneity is strongly associated with water, which affects deposition of chemicals and organisms and affects physical erosion. But there is not yet a systematic understanding of the roles of water, thin-film diffusion, precipitation in thin films, and advective inoculation of microbes from surface to subsurface soils in creating the heterogeneous nature of the soil environment.

\section{Snow, Ice, and Frozen Water}

Snow, ice, and frozen water in soils are an extremely important phase in the environment. With regard to snow, issues at the microscale have to do with grain-boundary interactions and grain-grain associations called sintering. Both the process by which sintering occurs, and the evolution of grain-grain interactions over time are uncertain. Yet these processes are fundamental to understanding snowpack stability.

Another topic is snow pack impurities. What is the association, at the microscale of atmospherically or other-originating, of impurities with snow grains? What can be an explanation for the temporal evolution of impurities relative to snowmelt water? Obviously, these questions bear upon water quality.

Also in the context of frozen water is frozen soils. Josh Schimel studies soils in the tundra and has shown that respiration continues in permafrost well past expected low temperatures. At the microscale, what is the ordering of water that would allow this? Do microbes produce antifreeze type compounds in their extracellular matrix that would enable frozen water to remain unfrozen? What is the processes by which nutrient resupply to unfrozen microbes occurs in this system?

\section{Concerns and Needs}

As our world is revolutionized by artificial nanosystems and nanotechnologies, new concerns arise. At a recent EPA conference on nanotechnologies in the environment, a researcher reported that DLVO theory, which is used to explain the balance of long and short range, attractive and repulsive, forces acting between particles, is not applicable to nanoparticles. Other theories must be discovered/invoked to explain interactions of nanoparticles with one another in suspension. What are these theories? What is the fate of manmade nanoparticles in the environment? How can we predict their fate if we cannot predict their interactions with water and with each other?

To address these questions, a battery of methods are needed, including modeling (mathematical, conceptual); direct observation by microscopy (ESEM, cryo, confocal, AFM, epi-fluorescence, tomography, image analysis), which is invaluable for formulating new hypotheses; molecular biology (gene reporter systems); model experimental systems (2-D micromodels, biofilm cultivation systems, porous media systems, systems including environmental variations like water potential); analytical chemistry (NMR, synchrotron methods, other spectroscopy, GCMS); physical chemistry (much of material science); and collaboration across disciplines. Particularly because the toolkits needed for the research are difficult to acquire, earnest collaboration (beyond the construction of a proposal) needs to occur. We need to find ways in which disparate disciplines and attitudes can come together to solve tough problems. 


\section{A River Runs Through It: Of Reaches, Riparian Zones, and Recharge Clifford Dahm, Professor of Biology, University of New Mexico}

Much river reach, or riverine corridor, understanding today is the result of integrated interdisciplinary research carried out by teams with diverse expertise. The river reach diagram in Figure $\mathrm{C} 2$, derived from an international workshop (Stanford 1998), depicts the components of a river reach, including an active flood plain, riparian zones, upslope components such as terraces, and complex dynamics that occur in vertical and horizontal directions. Much research is now focused on vertical interactions such as movement between surface water and groundwater and from upslopes into river reaches.

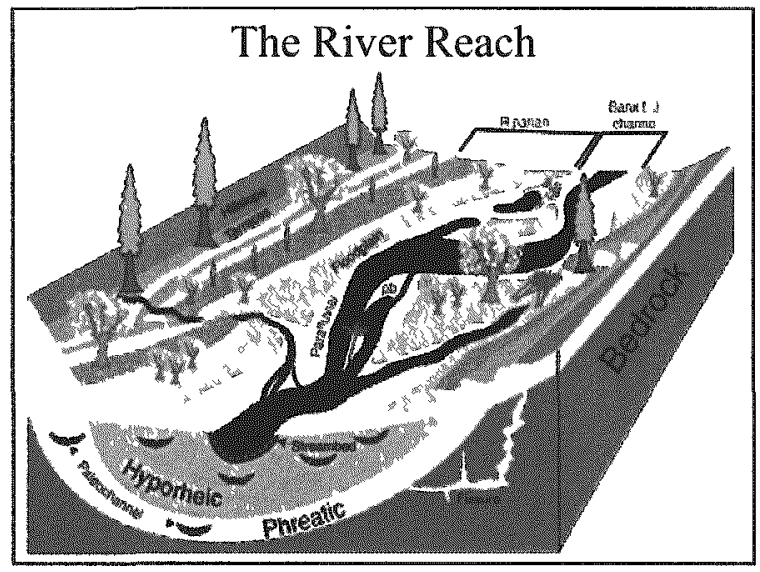

Figure C2. This shows the interactions between surface and groundwater, movement from upslopes in the river reach (after Stanford 1998).

The river continuum concept, published by Vannote et al. (1980), is one of the most cited papers on stream and river ecology, focusing on how rivers change longitudinally from headwaters to the ocean. This conceptual basis of studying rivers was then enhanced by studies of large river systems, such as the Amazon, to include the flood pulse concept (Junk et al. 1989). This added the importance of the lateral dimension - the interaction between the river and its flood plain.

The serial discontinuity concept was an attempt by stream and river ecologists to add human dimensions such as dams, diversions, and levees explicitly to riverine systems (Ward and Stanford 1995). In addition damsd, the hyporheic corridor concept has been an attempt to explicitly bring in the third dimension of interaction between surface water and groundwater, which is critical to many river system functions (Stanford and Ward 1993).

Here, two systems are discussed, both of which have 10 to 15 years of work at the reach scale and are end members of a continuum: the Flathead River in Montana (natural)

(Stanford et al. 1994) and the Rio Grande River, New Mexico (heavily human impacted) (Molles et al. 1998).

The Nyack floodplain of the Flathead River is a natural research area with minimal human impact that has been the focus of interdisciplinary research since the late $1980 \mathrm{~s}$. Early studies demonstrated the importance of the geomorphic template and the hydrologic interactions between surface water and groundwater. As shown with detailed discharge measurements, a substantial amount of flow is actively exchanged between the surface and subsurface in alternating losing and gaining reaches. This active interchange of water allows for the formation of a dynamic subsurface ecosystem. Studies have found 70 to $90 \%$ of the total aquatic invertebrate productivity likely occurs in the subsurface groundwater system, not in the benthic environment.

Coupled hydrologic, geomorphic, biogeochemical and ecological research at the Nyack floodplain has found complex, productive, subsurface food webs. Furthermore, the productivity and biomass at the surface tends to be linked to groundwater discharge and upwelling zones. There is selectivity by the fish community to seek out appropriate hydrologic 
conditions in which to feed and lay their eggs; for example, salmonids at groundwater discharge points. The vascular plant species distributed on the floodplain have higher richness in upwelling regions and there is faster cottonwood growth and higher leaf nitrogen content in upwelling zones compared to downwelling zones.

In contrast, the Middle Rio Grande in New Mexico, a 300-km reach, has major human impacts; more than half the population of New Mexico lives here. The upper portion has perennial flow, but there are increasingly periods of no flow below Albuquerque. Human activities have clear biological and chemical effects.

In 1930 , there was a wide, shallow, braided river floodplain with patches of vegetation spread throughout, but not in continuous riparian areas that are found today. Today, the river is a single channel with little braiding, and vegetation has moved into old channel areas-particularly nonnative species such as salt cedar and Russian olive. About $20 \%$ of the native cottonwood has disappeared to be replaced by monotypic stands of non-native species. The biggest loss is river channel wetlands, which have been reduced by more than half.

The changing dynamics of the floodplain affect the system's water budget. Since 2000 , micrometeorology and three-dimensional eddy covariance technology has been used to get better water use estimates by both native and non-native species. Site comparisons show that water use by different vegetation types, native and non-native, are highly variable. Efforts are now being made to scale up information at the stand level to develop an understanding of processes and water use at the riverine corridor scale. This research and the resulting GIS maps are then used to inform management and restoration decisions.

Examination of this impacted floodplain has shown that flow modification changes the composition and distribution of the riparian forest. This has implications for water depletions through evapotranspiration. Water quality also plays a role in aiding the spread of nitrogen-loving, non-native plants. The main disturbance regime, which was traditional flooding, is now primarily fire.

\section{Next Steps}

Interdisciplinary team research involving physiological ecologists, aquatic ecologists, hydrologists and other types of investigators must continue. In arid regions, the interplay among evaporation, transpiration, recharge and discharge is a fundamental question that we cannot yet parse out along the riverine corridor. One approach is to develop an Evapotranspiration-Recharge (ETR) array. ETR arrays link research along riverine corridors with instrumentation of shallow groundwater, the vadose zone, and eddy covariance systems to measure ET, plant-based measurements of water use, and monitor system stage and discharge. This facilitates research about how much water loss is from ET and how this affects surface water flow and groundwater recharge and discharge. In addition, it helps identify methods to restore ecosystems and increase flow where non-native species have taken over.

It's also important to link ecosystem theory and new technologies for studying biodiversity, water quantity, and water quality in a variable and changing climate. Large-scale technologies such as remote sensing and GIS are increasingly important, as they allow us to map onto the landscape important processes such as inundation patterns, temperature regimes, leaf area index, vegetation cover, water use estimates, and habitat type. These kinds of products will spin off to water managers and are also useful in planning and designing restoration projects. Well-designed interdisciplinary study like this can feed back into and enhance theories of how river reaches function. 


\section{Are Large Watersheds More Complex Than Small Watersheds?}

George Hornherger, Ernest H. Ern Professor, Department of Environmental Sciences,

University of Virginia

Watersheds (or catchments) are a fundamental unit of study in hydrology-- they represent a definable landscape unit where the inputs of precipitation are bounded by the catchment divides, and ostensibly, all of the water draining from the catchment exits at the catchment outlet. It's a natural unit for studying input/output relationships of water and associated dissolved and suspended materials.

Small watersheds tend to be more homogeneous with respect to inputs, geologic substrate, and vegetative cover. Therefore, small watersheds are presumably less complex than large watersheds. Hubbard Brook is one of the bestknown, on-going watershed/geochemistry studies. They have shown, for example, that the effects of clear cutting are season-dependent with decreased flows during the growing season and increased flows during the dormant season (Hornbeck et al. 1997). It was argued that the dormant flows from snowmelt occurred earlier, because once trees are cut down, the energy balance at the surface changes. However, complexity can be found in small watershed studies. At the H.J. Andrews Experimental Forest, Jones et al. (2000) did a classic study showing that road networks contribute to peak flows and modify landscape-scale response to floods. This is not as simple as may have first been thought. Roads have a destabilizing effect, lead to debris flows, and change channel characteristics-thus stream flow and flood response.

There have been a host of important outcomes, both physical and biogeochemical, from small catchment studies, including the processing of acidic atmospheric deposition and its effects on soil and stream water. While plenty of heterogeneity and complexity has been discovered with small catchment studies, the approach has been fairly reductionist. Sampling is done at points (or plots) around the catchment and numerical models are used to scale up to the catchment scale. With technological and computational advances, more and finer measurements are made and finer resolution numerical models are enabled.

An explicit, or at least implicit, goal of catchment research has been to scale up to large watersheds. The success of this venture is questionable. Hirsch (1998) said in regard to USGS small watershed investigations, "[ $t]$ he challenge for the coming decade will be for small watershed investigations to improve understanding of the effect of human influences on natural systems and to provide information for the restoration of damaged watersheds."

Even for small watersheds under careful study, it's often difficult to claim much success in reaching general "laws." Applying small-scale "physics-based" models and scaling up to the catchment has not been very effective. Hibbert (1967) stated that how a watershed responds to change in forest cover is "extremely variable, and, for the most part, unpredictable." Much is learned from these catchment studies, but we are not necessarily getting closer to making overall generalizations of behavior nor generalizations that can be extrapolated to larger systems. Such research tends only to contribute to understanding of the system under study. New approaches and methodologies are needed to move towards broader understanding.

The branching pattern in many drainage systems is a fractal pattern. One question is how such observations can be used to determine general quantitative scaling relationships for catchments. How can the behavior of large, complex watersheds be studied? Can "scaling" relationships in hydrology and hydrochemistry be more than a pixel-by-pixel assembly? 
Perhaps the best examples of an approach to take come from geomorphology. Consider Hack's Law (Hack 1957), which indicates that as basins get larger, they elongate. You can take empirical scaling relationships and then start to ask questions at the appropriate scale by making assumptions on how channel networks evolve. Much work has been done on this with computer simulations of river networks. You can assume that 1) there is minimum energy expenditure in any link of the network for a given discharge, 2) there's an equal energy expenditure per unit area of channel anywhere, and 3) there's a minimum energy expenditure in the network as a whole. Then you can use parameterizations of how energy gets expended by eroding channels and transporting water and materials. Such approaches can be used to formulate theoretical frameworks with empirical evidence that can used to interpret observations and data.

In hydrology, regression approaches have been used to extrapolate and scale data. Although effective, it may not provide enough understanding to make predictions in light of environmental change. Stochastic ecohydrological modeling is an approach for linking process information across scales that has yielded counter-intuitive results. For example, such models of the Colorado Short Steppe Grasslands have shown interesting inverse soil texture effect. The same plant found on coarse textures for dry climate and fine texture soils for wet climate (Porporato et al. 2002), the reverse of what might be thought if you were simply thinking along the lines of water potential relationships.

We have greatly expanded our database for water in the past several decades. We are on the verge of an even greater explosion of data acquisition in the next decade-from microscale sensor arrays to space-based remote sensing. We need to develop a theoretical framework for analyzing and interpreting these data, or we run the risk of devaluing the work by creating more place-specific understanding.
The challenge is to develop a hierarchical approach for the development of scientifically based scaling relationships to quantify watershed behavior. We need the fundamental measurements at the small scale but it's not simply a matter of multiplying these measurements out to larger scales. In a paper by Dodds and Rothman (2000), four hierarchical scaling regimes are postulated ranging from non-convergent hillslope flow, an intermediate region of shortrange order with unknown scaling, random networks, and up to geologic controls.

There is complexity at all scales in hydrology. Environmental scientists working at different scales tend not to interact. The problems of figuring out how to use measurements of microbial respiration at a very small scale, for example, to understand temporal patterns of DOC export from a small catchment is very difficult. We need a framework to link these scales and information. We need formulation of hypotheses at the large scale in particular. We need to know how conservation laws will scale, and how small-scale details will be parameterized. We need interaction among scientists working at different scales and hierarchical data and experiments.

\section{Submarine Groundwater Discharge: A Lesser-Known Route for Material Exchange Across Land/Sea Margins Peter Swarzenski, Chemical Oceanographer, United States Geological Survey}

The discharge of groundwater into the ocean has long been a keen topic of interest. Before 79 A.D., Pliny the Elder noted that "freshwater may be drawn from the sea in a great many places, as at the Swallow Islands and at Aradus (Syria) and in the Gulf of Cadiz." More than 3000 years ago in Ruad, Syria, the Phoenicians built a submarine groundwater collection system that supplied water to the city of Amrit. Today, 
scientists are proposing tapping of submarine freshwater springs off of Jeddah in the Middle East.

Despite its long history, only very recently has there been a concerted effort to look at the science of SGD. The first SGD Symposium was held in 1996 in Moscow. This conference, organized by Bob Buddemeier (Kansas Geological Survey) and Igor Zekster (Russian Academy of Sciences) was the first time researchers in this field had an opportunity to meet.

SGD is defined as any flow out across the seabed of the continental shelf, regardless of composition or driving force. It's not just fresh groundwater bubbling up. SGD is not defined on the basis of components, origin, or driving forces. It is composed of meteoric waters, connate waters, and recirculated seawater (Figure C3). It can be expressed as seepage at the shore phase, through a submarine spring, or as a brackish pore water recirculation zone.
Some of the processes driving SGD are hydraulic gradient (Darcy's law) on the terrestrial side and tidal pumping, wave setup, current-induced topographic flow, convection, and sea-level differences on the marine side. Fluid flow is often induced by differences in water level across a barrier--this flow may be entirely recirculated seawater, or it may be a mixture of surface water and freshwater if a freshwater lens exists.

Global estimates of SGD are all over the map they range from 100 to $3000 \mathrm{~km}^{3} / \mathrm{y}$. SGD is highly variable in time and space. It tends to be high in areas with high rainfall, high relief, fractured rock, poorly developed river systems, and karst features. Chemical inputs via SGD almost certainly exceed freshwater inputs because of high concentrations of TDS in groundwater versus river water.

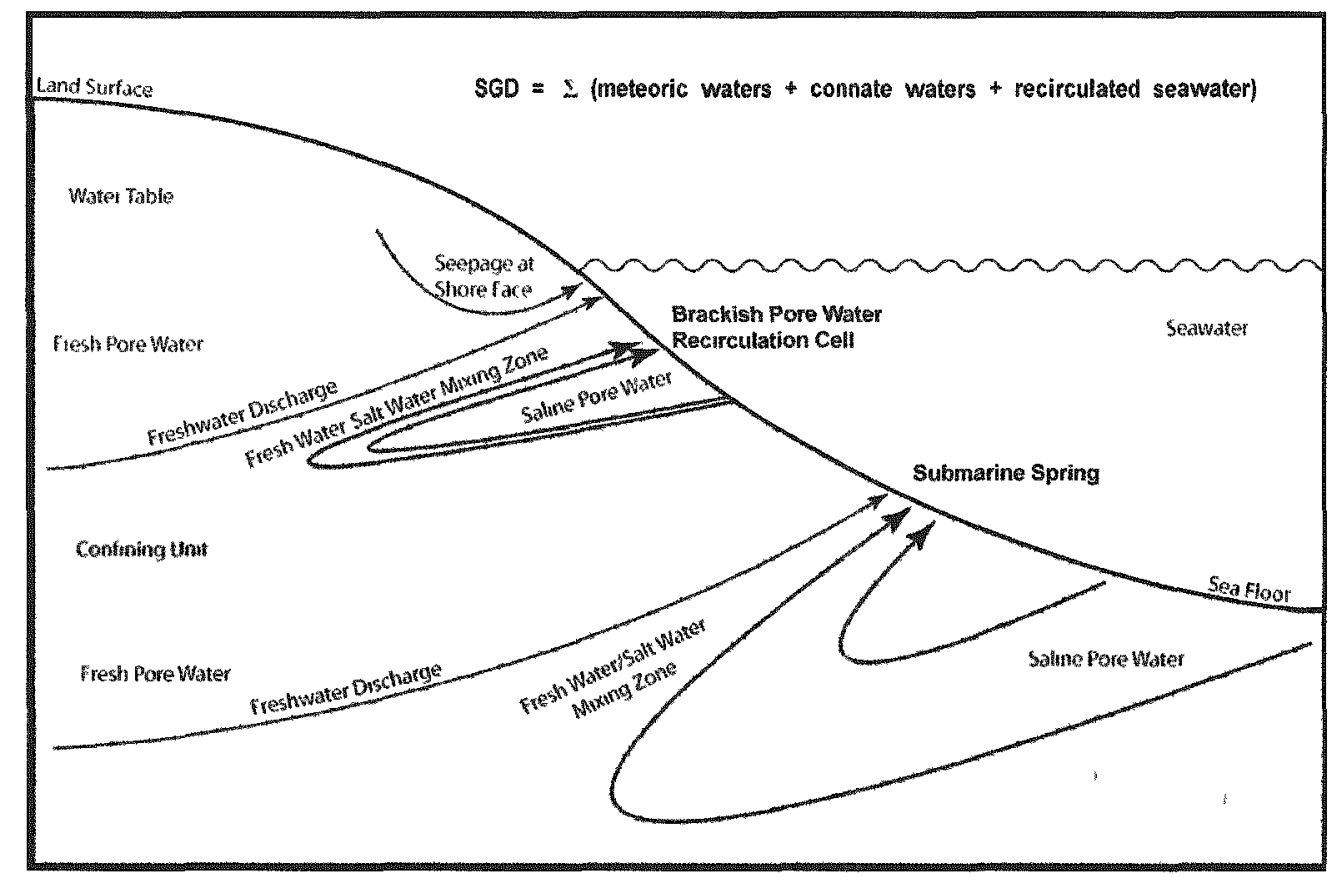

Figure C3. Idealized hydrogeologic cross-section depicting the freshwater/salt water interface. Note that submarine groundwater discharge (SGD) may reflect diverse water masses that may be influenced by a wide range of distinct coastal processes. 
The process of SGD is inherently difficult to measure because rates are most often very low and very diffuse. There are also real differences in the terminology used by hydrologists and oceanographers alike. However, the SCOR working groups and workshops such as this one are helping to address these different perspectives.

Oceanographers make simple models to assess SGD discharge rates and mixing rates. In the coastal ocean there is high radium and radon; in the open ocean, both are very low. Radium and radon mass balance models can be used to quantify SGD rates in the coastal ocean. ${ }^{223} \mathrm{Ra}$ and ${ }^{224} \mathrm{Ra}$ may used to study how quickly water parcels move out of an estuary. Rosenau et al. (1977) showed a concentration of offshore springs in Florida. Five years later, Fanning et al. (1982) looked at bottom water radon concentrations and noted an increase in radon concentrations at these same sites. This gives more evidence of radon's usefulness as a tracer for water advection across the sediment/water interface.

Burnett and Swarzenski's groups have adapted a simple off-the-shelf air/radon monitor, and by the use of an air/water exchanger and knowing the partitioning coefficient and the temperature, they can look at the water column radon concentrations (Kim et al. 2001, Dulaiova et al. 2005). By using these in series, continuous radon concentrations can be obtained. Radon is also useful for looking for SGD sites. In Biscayne Bay, the continuous radon record shows a periodicity that obviously relates to the tidal cycle. Rn activities were at maximum shortly after the lowest tide, while seepage meters showed the maximum flux at the very lowest tide.

\section{Research Needs}

We need improved methodologies for direct assessments (e.g., less disruptive and more continuous in situ measurements). We also need to discriminate between various forces; (e.g., isotopic signatures; modeling different transport processes). Scaling up for regional assessments (e.g., combine isotopes with remote sensing, geophysics) is needed. Studies are needed to evaluate effects of climate change on SGD: change in sea level will cause a shift in groundwater fluxes from continents to the oceans.

In summary, some of us recently authored an attempt at a synthesis volume for Land-Ocean Interactions in the Coastal Zone (LOICZ) and a new special issue of Biogeochemistry-this meeting should help us decide the feasibility of synthesis. Rather than being in the "exploratory" stage as suggested by Valiela and D'Elia (1990), we are now in the "discovery" stage - much remains to do, but we're starting to see real progress.

\section{Water and Environment at the Ocean Interface}

John Melack, Professor of Biological Sciences, University of California at Santa Barbara

Several issues pertaining to ocean margins, particularly the terrestrial-ocean interface, will be discussed beginning at the global scale. Perhaps surprisingly, it is sometimes easier to start by asking questions at the global scale and then jump directly to the scale relevant to the issues identified by a particular problem. Scale does not have to be addressed linearly, and all scales may not need to be included. After examining global-scale examples, higher frequency measurements and regional- and local-scale analyses, where most human interactions occur and understanding can be more mechanistic, will be considered.

\section{Global Scale}

Smith et al. (2003) used population densities and runoff to develop a series of regression equations to estimate the export of dissolved 
inorganic phosphorus and nitrogen from the coastlines of all the continents. With the exception of a few hot spots, they found most of the coastlines are similar in terms of export

when expressed per unit area. When actual loading is examined, the affects of high discharge areas and water enriched in nutrients by human activities can be seen. This analysis was based upon data collected from 160 catchments distributed around the world (Figure C4). Large catchments were fairly well represented while small and meso-scale catchments were not. It is important to bear in mind that any regression analysis is limited by the underlying data.

Using a more sophisticated, although still regression-based, GIS approach, Green et al. (2004) looked in greater detail at nutrient loading. Their assessment included estimates of nitrogen fixation, sewage, and fertilization combined with simple parameterizations of how residence time and temperature affect the processing of the nitrogen moving off the landscape. By adding a water balance-based calculation of discharge, they distribute the loading temporally as well as spatially.

This analysis presents an opportunity to jump scales. On a global average, about $20 \%$ of the nitrogen loading to the landscape is exported in river discharge. Where is the remaining nitrogen going? The current consensus, albeit without much data, is that it is lost through denitrification -a microbial process occurring at the nanoscale where site-specific redox conditions occur. Therefore, we have to move directly from the global scale to the scale of microbial activity to propose an explanation for the fate of the nitrogen.

Human activities can also influence nutrient export from the landscape. For example, dams and the resulting reservoirs can have a large impact on nutrient processing and export, and on carbon sequestration, by increasing the residence time of water. Organic carbon sequestration in reservoirs appears to be similar to that in the world's oceans even though reservoirs are less

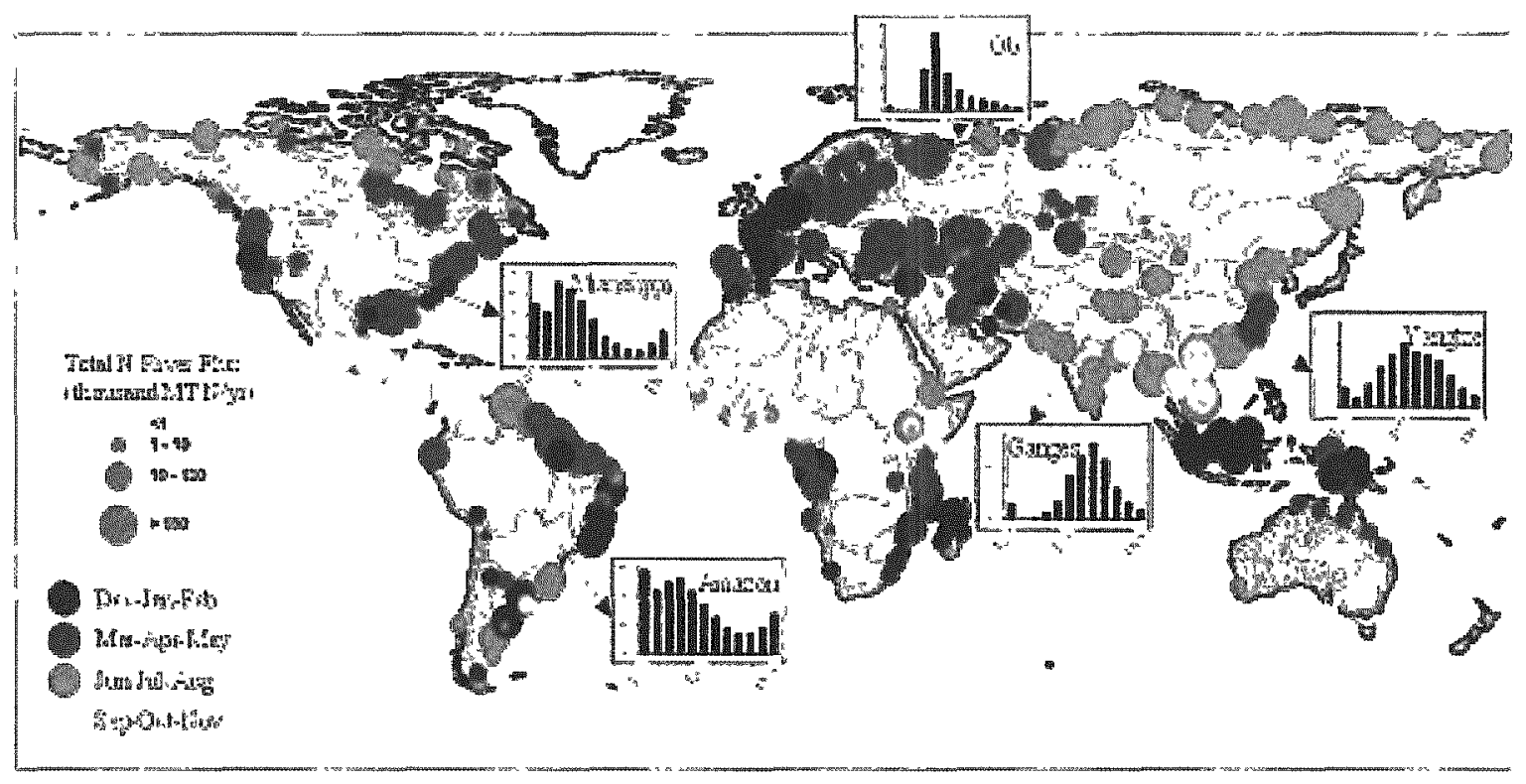

Figure C4. Catchments used to estimate dissolved inorganic nitrogen and phosphorus fluxes to coastal ocean (Smith et al. 2003). 
than $1 \%$ of the landscape. Dams create hot spots-discrete locations on the landscape with processes occurring at high rates that are important at multiple scales. Simply considering spatial extent may not be sufficient

\section{Regional Scale}

Along the Santa Barbara Channel, there are about 75 small catchments $\left(1-50 \mathrm{~km}^{2}\right)$. If we apply Smith et al.'s (2003) approach to $120 \mathrm{~km}$ of coastline, comparable to just 1 unit of their global study, we can examine a region with considerable data and a wide range of land use. With a carefully designed sampling program within basins and at the outlet of basins, a large range in nutrient export across land use types and substantial interannual variability is observed. This approach of examining nested scales demonstrates the spatial heterogeneity at the regional scale and has conceptual as well as empirical value. Going one step farther, if these data are used to do a regression-based analysis of land use and flow characteristics combined with a regional rainfall-runoff model, one can calculate, for each catchment, the pattern of export and total flux going into the ocean.

Another aspect of export from catchments is particulate matter. A common way to examine particulate flux is to use remote sensing data, such as SeaWiFS, to estimate suspended sediment concentrations following large runoff events. While such data can provide a valuable perspective, they can be misleading. The remotely sensed sediment concentrations in plumes from the Santa Clara and Ventura rivers are only $1 \%$ of the actual sediment export from those rivers. Most of the sediment enters the Channel at a depth greater than the detection limit of the satellite-borne sensors. Furthermore, SeaWiFs can only capture the ocean at about a kilometer offshore. Many near-shore processes and interactions are not within its detection capability.

\section{Local Scale}

At the local scale of terrestrial-ocean interaction, beach contamination and closure is a common issue. In 2002, 5000 U.S. beaches were closed based on plate counts of indicator organisms. Decisions to close beaches are made based on $19^{\text {th }}$ century methodology, and only a subset of potential pathogens is included. This is a major area of public interest, where scientists can help agencies improve their measurements by merging modeling with modern technology and current understanding.

The hydrologic response unit concept is a traditional approach to scaling. Subdividing catchments into units of on the order of a square kilometer tends to capture many of the appropriate processes. When applied to the Mission Creek subcatchment along the Santa Barbara coast, some seemingly counterintuitive results were found. The lower, urban subcatchment had exported less nitrate than the undisturbed upper catchment. Using isotopic signatures of oxygen and nitrogen in nitrate, different sources (e.g., soil or atmospheric deposition) of nitrate can be distinguished. For example, data from the Sierra Nevada show that the initial phase of nitrogen export is from the soil, and the later phase is from the atmospheric deposition in snow.

Another local factor is how wetlands and estuaries interface with the ocean. A University of California-Davis study is examining how contaminants influence marsh plants. Using newly available LIDAR systems, Susan Ustin's group has images showing distribution patterns in which multispectral high-resolution remote sensing data are superimposed to identify individual plant species. They experimentally treated these plants with cadmium and examined the reflectance spectrum to determine changes in the reflectance as a function of cadmium concentration. This study merged hydrologic modeling, contaminant chemistry, biogeochemical processes, and remote sensing to examine 
plant response. Understanding at these types of interfaces should be further pursued at multiple scales.

\section{Science and Methodology}

Understanding is currently limited by both data and concepts. Though we have the ability to do some in situ, near-real-time, and high frequency (e.g.. conductivity) measurements, others remain technically difficult (e.g., nitrate and phosphate) or very expensive (e.g., dissolved organic carbon). Real-time data are collected infrequently, and we are still learning how to use the information generated. For example, the California Department of Water Resources placed a realtime dissolved organic carbon (DOC) analyzer in the Sacramento Delta. The patterns observed in the data raised more questions than they solved. Sampling frequency must correspond to the question; high frequency or real-time sampling can help answer questions that could not be addressed with weekly sampling regimes. Although progress is being made, we are still not adequately served in our data collection systems.

In all of the systems discussed, fluxes are not just to the ocean. There are also vertical fluxes into the sediments and exchanges with the atmosphere. For example, we can characterize the Amazon basin using remote sensing methods to assess the flooding dynamics and combine those with measurements of $\mathrm{pCO}_{2}$ in the rivers and wetlands to calculate how much $\mathrm{CO}_{2}$ is entering or leaving those systems. There is about half a gigaton of $\mathrm{CO}_{2}$ outgassing from rivers and wetlands to the atmosphere per yearmore than 10 times the total Amazon export of either DIC or DOC to the oceans. Even though the Amazon accounts for $20 \%$ of the annual river discharge to the ocean worldwide, the atmospheric exchange is much larger. Hence, it is important to consider air-water exchange in addition to fluxes in water. New technologies are under development, but we still need to make them deployable in remote locations.
Technological challenges still remain in measuring water flow. There are new in situ sensors such as stage-temperature data logging systems and acoustic Doppler current profilers. But large wetland systems, such as vast flooded regions in the tropics and boreal zones, and braided river systems are hard to measure. Traditional gauging methods are not applicable to these environments. For the biggest rivers in the world, true challenges remain to get even a decent discharge measurement. much less the associated chemistry and biology information.

\section{Promising Approaches}

Microwave remote sensing is very powerful as a remote-sensing tool. Large-scale inundation can be determined from passive microwave analysis. where data are available globally every 3 to 5 days. Radar altimetry can be used to determine changes in height of ocean surfaces as well as to measure river and wetland stage in large systems. Synthetic aperture radar enables studies of flooding and vegetation. SAR interferometry allows a look at very small-scale water level variations. Modeling the flow through these complicated aquatic systems depends on detailed digital elevation models and knowing the water slope. This information is relevant to issues such as the growth of aquatic organisms and pollutant distribution. These new methodologies are not being sufficiently utilized.

Remaining challenges include 1) communication and coordination among hydrology and terrestrial and aquatic ecology, 2) in situ and remote sensing of biological and chemical constituents and hydrologic conditions, 3 ) predictive models of dynamic systems including climate and land use change, 4) data access and data management, and 5) interactions with resource managers and policy makers. 


\section{Climate Impacts on the Water Cycle}

\section{Ruby Leung, Laboratory Fellow: Pacific Northwest National Laboratory}

The focus of this talk is precipitation, a very important component of the climate system that affects the water cycle. on the regional to global scale. Precipitation is the major driver of land surface hydrology, yet it is the most uncertain part of the hydrologic cycle. Globally, precipitation is balanced by evaporation, but regionally, the differences between precipitation and evaporation varies significantly.

Precipitation varies at all temporal and spatial scales. presenting challenges in monitoring. modeling, and prediction. In monitoring, the challenges are sampling frequency and location and how to relate point measurements to grid averages. In modeling, we need to parameterize subgrid scale processes and feedbacks. To meet the needs of diverse users, we need predictions at a large range of temporal and spatial scales, and extremes such as floods and droughts matter.

Most precipitation comes from moisture derived from ocean evaporation, which does not precipitate locally. Regionally, precipitation is largely controlled by atmospheric moisture flux. Large-scale moisture transport is governed by circulation induced by heat sources and sinks and a rising motion is required to produce condensation. Cloud microphysics also has a large impact on precipitation characteristics.

Challenges of predicting the hydrological cycle lie in the large temporal and spatial variability. Examples of precipitation variability are found in the Sierra Nevada and coastal ranges, where although the mountain has a large influence on precipitation, the large-scale circulation also plays an important role. The interaction of the large-scale flow and regional forcing must be considered. In California, changes in large-scale conditions from year to year can result in large differences in how moisture is partitioned between the two coastal mountains and how moisture is partitioned between the windward and lee side of each mountain. Furthermore, there appears to be some bimodal behavior, especially over the Sierra Nevada, which is attributed to variability associated with the El Nino-Southern Oscillation (ENSO) (Leung et al. 2003).

Good predictions of both temperature and precipitation are needed for prediction of seasonal runoff. Other climate issues at the longer time scales include impacts of global warming, air pollution, and land use change on water resources, the water cycle, and the role of land surface in droughts, respectively.

When projecting long-term trends in the hydrological cycle, simple arguments can be used to examine the global trend. The ClausiusClapeyron equation for the change in saturation vapor pressure implies that a warmer atmosphere can hold more water. Therefore, greenhouse warming increases evaporation, and increased evaporation increases precipitation equally on a global scale. The actual increase in evaporation is limited by surface heat budget. On a regional basis, precipitation may increase at a rate permitted by the Clausius-Claperyron equation for the water holding capacity, which is higher than that simulated by climate models for the global average under the energy constraint. Hence, potentially the frequency for both floods and droughts may increase at the regional scale in a warmer climate (Trenberth 2003).

There have been recent arguments that the global hydrologic cycle is accelerating. Following the arguments of Ramanathan et al. (2001), the global mean land average rainfall has decreased since the 1950 s despite warmer temperatures. At the same time, fossil fuel black carbon emissions have increased by a factor of -2.5. Aerosols reduce surface solar radiation, which must be balanced by reduced evaporation. which in turn leads to decreased precipitation. 
However, simple arguments can only go so far. Nonlinearity, physical constraints, and forcing and response must be considered on a regional as well as global basis to improve our estimates of climate sensitivity. The big question is, "How will water resources change globally and regionally?"

Climate models are used to sort out the various forcings such as greenhouse gases and aerosols and response and for making climate predictions into the future. Global climate models (GCMs) are the most comprehensive modeling tools used to develop climate scenarios for the future.

However, because of complexity and global coverage, GCMs are typically applied at relatively coarse spatial resolution of 150 to $300 \mathrm{~km}$ despite advances in computer architectures and software.

Because the terrestrial water cycle is strongly affected by regional scale forcing such as orography, climate impact assessment must be performed at the regional scale to provide useful information for managing water resources. As a dynamical downscaling tool, regional climate models (RCMs) have advantages over GCMs in modeling seasonal and diurnal variations of precipitation, extreme climate events, and regional scale climate anomalies. We have applied a RCM nested within the NCAR GCM to the western U.S. to examine the impacts of climate change on water resources (Leung et al. 2004). We examined an ensemble of three future climate simulations based on $1 \%$ increase in $\mathrm{CO}_{2}$ per year. The GCM simulations showed an almost linear trend in the temperature response over the western U.S. with a warming of 1.5 to $2^{\circ} \mathrm{C}$ by mid-century, with little change in precipitation.

Through downscaling, more detailed climate change signals were obtained over the western U.S. A main difference between the temperature change simulated by the GCM and RCM is found along the coastal mountain ranges such as the Cascades and the Sierra Nevada. With higher spatial resolution, the RCM was able to capture the snowpack along the narrow mountain ranges and the potential large reduction in snowpack of up to $70 \%$ as a result of greenhouse warming. As a result of snow-albedo feedback, the RCM simulations show larger temperature change along the coastal mountains. In addition, the RCM also suggests larger change in extreme precipitation over the Cascades and Sierra.

When applying the RCM simulations to a distributed hydrologic model of the Yakima River basin, results show a large reduction in snowpack caused by the warming. In a warmer climate, more precipitation will take the form of rain rather than snow and contribute more directly to runoff during the winter to increase the likelihood of wintertime flooding. Since snowmelts occur earlier in a warmer climate, there will be a significant shift in the early summer peak in runoff. Such changes in the seasonal cycle of runoff have large impacts for water management in a region where water is managed for multiple objectives including flooding control, hydropower generation, and irrigation.

Comparing the model projections for the next 50 years with what we have seen in the past 50 , a similar degree of warming was found that leads to large reductions in snowpack (Mote et al. 2003). Consistent with model projections, the timing of streamflow in river basins has shifted towards earlier peaks by up to 35 days or more across the western U.S. (Stewart et al. 2004).

In summary, our climate change study showed that climate change will likely lead to warmer conditions, reduced snowpack, and large changes in runoff beyond the natural variability we have seen in the past. RCMs are needed to provide climate scenarios at the regional scale to assess climate impacts on water resources. However, the impacts of climate on water resources were examined using uncoupled models of the climate and surface hydrology. 
Such an approach is necessary because biases in all climate simulations must be corrected to yield realistic simulations of surface hydrology.

A research need in applying climate model results to water management is to develop more sophisticated methods for extracting climate information from climate models, including the consideration of uncertainties arising from model formulations and emission scenarios. Lastly, even with RCMs, additional downscaling is often needed to apply the regional scale climate scenarios to hydrologic models that are of much finer spatial scales. Hence, there is a continuing need to develop scaling methods to link across the global, regional, and local scales of the water cycle. 


\section{Appendix D - Report and Lecture References}

Beven K. 2001. "How far can we go in distributed hydrological modeling?" Hidrol. Earth Sist. Sc. 5(1):1-12.

Bryers JD, ed. 2000. Biofilms II: Process Analysis and Applications. Wiley-Liss, Inc., New York.

Characklis WG and KC Marshall. 1990. Biofilms. Wiley, New York.

Costerton JW and HM Lappin-Scott. 1995. "Introduction to microbial biofilms." In Microbial Biofilms eds HM Lappin-Scott and JW Costerton. pp. 1-11. Cambridge University Press, Cambridge, United Kingdom.

Costerton JW, Z Lewandowski, D DeBeer, D Caldwell, D Korber, and G James. 1994. "Biofilms, the customized microniche." J. Bacteriol. 176:2137-2142.

Dodds PS and DH Rothman. 2000. "Scaling, universality, and geomorphology." Ann. Rev. Earth Planet. Sci. 28:571-610.

Dulaiova H, R Peterson, WC Burnett, and D Lane-Smith. 2005. "A multi-detector continuous monitor for assessment of ${ }^{222} \mathrm{Rn}$ in the coastal ocean." J. Radioan. Nucl. Chem. 263(2):361-365.

Fanning KA, JA Breland, and RH Byrne. 1982. "Radium-226 and radon-222 in the coastal waters of West Florida; high concentrations and atmospheric degassing." Science, 215:667-670.
Futrell JH et al. 2003. Environmental Cyerinfrustructure (ECI): Tools for the Stud. of Complex Environmental Systems. AC-ERE 1. Advisory Committee for Environmental Research and Education, National Science Foundation, North Arlington, Virginia.

Gleick PH. 2003. "Global freshwater resources: Soft-path solutions for the $21^{\text {st }}$ century." Science 302:1524-1528.

Graham PG, EA Bestland, and GS Walker. 2004. "Distinguishing sources of base cations in irrigated and natural soils: Evidence from strontium isotopes." Biogeochemistry 68(2):199-225.

Green PA, CJ Vorosmarty, M Meybeck, JN Galloway. BJ Peterson, and EW Boyer. 2004. "Pre-industrial and contemporary fluxes of nitrogen through rivers: a global assessment based on typology." Biogeochemistry 68:71-105.

Hack JT. 1957. "Studies of longitudinal stream profiles in Virginia and Maryland." USGS Prof. Pap. 294-B:45-97.

Hibbert AR. 1967. "Forest treatment effects on water yield." In Forest Hydrology' Proceedings of a National Science Foundation Advanced Science Seminar, eds WE Sopper and HW Lull, pp. 527-543. Pergamon Press, Oxford.

Hirsch RM. 1998. "Small watershed investigations in the U.S. Geological Survey." EOS. Transactions, American Geophisical Union 79:S124.

Holden PA, JR Hunt, and MK Firestone. 1997. "Toluene diffusion and reaction in unsaturated Pseudomonas putida biofilms." Biotechnol. Bioeng. 56(6):656-670. 
Holden PA, MG LaMontagne, AK Bruce, WG Miller, and SE Lindow. 2002. "Assessing the role of Pseudomonas aeruginosa surfaceactive gene expression in hexadecane biodegradation in sand." Appl. Environ. Microbiol. 68:2509-2518.

Hornbeck JW, CW Martin, and C Eagar. 1997. "Summary of water yield experiments at Hubbard Brook Experimental Forest, New Hampshire." Can. J. Forest Res. 27:2043-2052.

Jones JA, FJ Swanson, BC Wemple, and KU Snyder. 2000. "Effects of roads on hydrology, geomorphology, and disturbance patches in stream networks." Conserv. Biol. 14:76-85.

Junk WJ, PB Bayley, and RE Sparks. 1989. "The flood pulse concept in river-floodplain systems." In Proceedings of the International Large River Symposium, ed DP Dodge. Canadian Special Publication of Fisheries and Aquatic Sciences 106:110-127.

Kim G, WC Burnett, PW Swarzenski, and WS Moore. 2001. "Measurement of ${ }^{224} \mathrm{Ra}$ and ${ }^{226} \mathrm{R}$ a activities in natural waters using a radonin-air monitor." Environ. Sci. Technol. 35:4680-4683.

Leung LR, Y Qian, X Bian, and A Hunt. 2003. "Hydroclimate of the western United States based on observations and regional climate simulation of 1981-2000. Part II: Mesoscale ENSO anomalies." J. Clim. 16(12):1912-1928.

Leung LR, Y Qian, X Bian, WM Washington, $J$ Han, and JO Roads. 2004. "Mid-century ensemble regional climate change scenarios for the western United States." Climatic Change $62(1-3): 75-113$.
McClain, ME, EW Boyer, CL Dent, SE Gergel, NB Grimm, PM Groffman, SC Hart, JW Harvey, CA Johnston, E Mayorga, WH McDowell, and G Pinay. 2003. "Biogeochemical hot spots and hot moments at the interface of terrestrial and aquatic ecosystems." Ecosistems 6:301-312.

Molles Jr. MC, CS Crawford, LM Ellis, HM Valett, and CN Dahm. 1998. "Managed flooding for riparian ecosystem restoration." BioScience 48:749-756.

Mote PW. 2003. "Trends in snow water equivalent in the Pacific Northwest and their climatic causes." Geophvs. Res. Lett. 30(12):1601, DOI:10.1029/2003GL017258.

National Council for Science and the Environment (NCSE). 2004. Water for a Sustainable and Secure Future: a Report of the Fourth National Conference on Science, Policy, and the Environment, eds CM Schiffries and A Brewster. NCSE, Washington, D.C.

National Research Council of the National Academies (NRC). 2001. Envisioning the Agenda for Water Resources Research in the Twenty-First Century. National Academy of Sciences, Washington. D.C.

National Research Council of the National Academies (NRC). 2004. Confronting the Nation's Water Problems: The Role of Research. National Academy of Sciences, Washington, D.C.

Norling P, F Wood-Black, and TM Masciangioli, eds. 2004. Water and Sustainable Development: Opportunities for the Chemical Sciences. National Academy of Sciences, Washington, D.C. 
Pfirman S and the AC-ERE. 2003. Complex Environmental Systems: Sinthesis for Earth, Life, and Society in the 21st Century, A report summarizing a 10 -year outlook in environmental research and education for the National Science Foundation, $68 \mathrm{pp}$.

Philip JR. 1975. "Some remarks on science and catchment prediction." In Proc. Symp. Aust. Acad. Science, Canberra, Prediction in Catchment Hydrology, eds TG Chapman and FX Dunin, pp. 23-30. Australian Academy of Science, Canberra.

Porporato A, P D'Odorico, F Laio, L Ridolfi, and I Rodriguez-Iturbe. 2002. "Ecohydrology of water-controlled ecosystems." Adv. Water Resour. 25:1335-1348.

Ramanathan V and 38 co-authors. 2001. "Indian Ocean experiment: An integrated analysis of the climate forcing and effects of the Great Indo-Asian Haze." J. Geophys. Res. 106(D22):28371-28398.

Roberson EB and MK Firestone. 1992. "Relationship between desiccation and exopolysaccharide production in a soil Pseudomonas sp." Appl. Environ. Microbiol. 58:1284-1291.

Rosenau JC, GL Faulkner, CW Hendry Jr., and RW Hull. 1977. Springs of Florida. Geological Bulletin No. 31, revised, U.S. Geological Survey, Reston, Virginia.

Smith SV, DP Swaney, L Talaue-McManus, JD Bartley, PT Sandhei, CJ McLaughlin, VC Dupra, CJ Crossland, RW Buddemeier. RA Maxwell, and F Wulff. 2003. "Humans, hydrology, and the distribution of inorganic nutrient loading to the ocean." BioScience 53:235-245.
Stanford JA. 1998. "Rivers in the landscape: introduction to the special issue on riparian and groundwater ecology." Freshwater Biol. 40:402-406.

Stanford JA and JV Ward. 1993. "An ecosystem perspective of alluvial rivers: connectivity and the hyporheic corridor." J. N. Am. Benthol. Soc. 12:48-60.

Stanford JA, JV Ward, and BK Ellis. 1994. "Ecology of alluvial aquifers of the Flathead River, Montana." In Groundwater Ecology, eds J Gilbert, DL Danielopol, and JA Stanford, pp. 367-390. Academic Press, Inc., San Diego, California.

Stewart IT, DR Cayan, and MD Dettinger. 2004. "Changes in snowmelt runoff timing in western North America under a "business as usual" climate change scenario." Climatic Change 62(1-3):217-232.

Stocker TF and CC Raible. 2005. "Climate change: Water cycle shifts gear." Nature 434:830-831.

Trenberth KE, A Dai, RM Rasmussen, and DB Parsons. 2003. "The changing character of precipitation." Bull. Amer. Meteorol. Soc. 84:1205-1217.

United Nations World Water Assessment Programme (WWAP). 2003. UN World Water Development Report: Water for People, Water for Life. Paris, New York and Oxford, UNESCO (United Nations Educational, Scientific and Cultural Organization) and Berghahn Books, Barcelona.

Valiela I and C D'Elia, eds. 1990. Special issue: "Groundwater inputs to coastal waters." Biogeochemistry 10:328. 
Vandas SJ, TC Winter, and WA Battaglin. 2002. Water and the Environment. AGI

Environmental Awareness Series, 5. American Geological Institute, Alexandria, VA.

Vannote RL, GW Minshall, KW Cummins, JR Sedell, and CE Cushing. 1980. "The river continuum concept." Can. J. Fish. Aquat. Sci. $37(1): 130-137$.
Ward JV and JA Stanford. 1995. "The serial discontinuity concept: extending the model to floodplain rivers." Regul. River. 10:159-168.

Wurtsbaugh W, J Cole, D McKnight,

P Brezonik, S Macintyre, and K Potter (eds). 2003. Report of the Workshop on Emerging Research Questions for Limnology: The Study, of Inland Waters. American Society of Limnology and Oceanography, Waco, Texas. 